\title{
Inflammatory and age-related pathologies in mice with ectopic expression of human PARP-1
}

\author{
Aswin Mangerich ${ }^{\mathrm{a}, *}$, Nadja Herbach ${ }^{\mathrm{b}}$, Benjamin Hanf ${ }^{\mathrm{a}}$, Arthur Fischbach ${ }^{\mathrm{a}}$, Oliver Popp ${ }^{\mathrm{a}}$ \\ María Moreno-Villanueva ${ }^{a}$, Oliver T. Bruns ${ }^{c}$, Alexander Bürkle ${ }^{a, *}$ \\ "University of Konstanz, Molecular Toxicology Group, Konstanz, Gemany \\ ${ }^{\mathrm{b}}$ LMU Mutich, institute of Veterinay Pathology, Munich, Germany \\ 'University Medical Center Hamburg-Eppendorf, Department of Biochemistry and Molecular Biology II, Hamburg Germany
}

\begin{abstract}
A B S T R A C T
Poly(ADP-ribose) polymerase-1 (PARP-1) is a sensor for DNA strand breaks and some unusual DNA structures and catalyzes poly(ADP-ribosyl)ation of nuclear proteins with $\mathrm{NAD}^{*}$ serving as substrate. PARP-1 is involved in the regulation of genomic integrity, transcription, inflammation, and cell death Due to its versatile role, PARP-1 is discussed both as a longevity factor and as an aging-promoting factor. Recently, we generated a mouse model with ectopic integration of full-length $h P A R P-1$ |Mangerich, A. Scherthan, H., Diefenbach, J., Kloz, U., van der Hoeven, F, Beneke, S. and Bürkle, A, 2009. A caveat in mouse genetic engineering: ectopic gene targeting in ES cells by bidirectional extension of the homology arms of a gene replacement vector carrying human PARP-1. Transgenic Res. 18, 261-279]. Here, we show that $h P A R P-1$ mice exhibit impaired survival rates accompanied by reduced hair growth and prenature development of several inflammation and age-associated pathologies, such as adiposity, kyphosis, nephropathy, dermatitis, pneumonitis, cardiomyopathy, hepatitis, and anemia. Moreover, mutant male mice showed impaired glucose tolerance, yet without developing manifest diabetes. Overall tumor burden was comparable in wild-type and hPARP-1 mice, but tumor spectrum was shifted in mutant mice, showing lower incidence of sarcomas, but increased incidence of carcinomas. Furthermore, DNA repair was delayed in splenocytes of $h P A R P-1$ mice, and gene expression of pro-inflammatory cytokines was dysregulated. Our results suggest that in hPARP-1 mice impaired DNA repair, accompanied by a continuous low-level increase in pro-inflammatory stimuli, causes development of chronic diseases leading to impaired survival.
\end{abstract}

\section{Introduction}

Poly(ADP-ribose) polymerase-1 (PARP-1) is the founding member of the family of poly(ADP-ribose) polymerases (Hottiger et al., 2010; Schreiber et al., 2006). By using NAD $^{+}$as a substrate, PARP-1 synthesizes linear or branched biopolymers known as poly(ADP-ribose)(PAR) (Bürkle, 2005; Rouleau et al., 2010). One of the fastest responses of most eukaryotic cells to DNA damage is the binding of PARP-1 to DNA strand breaks, thus inducing PARP-1 dimerization and catalytic activation (Mendoza-Alvarez and Alvarez-Gonzalez, 1993; Pion et al., 2005). In addition, indepen-

\footnotetext{
* Corresponding authors at: Chair of Molecular Toxicology, Department of Biology, University of Konstanz, D-78457 Konstanz, Germany.

Tel.: +4975318840 35; fax: +497531884033 .

E-mail addresses: aswin.mangerich@uni-konstanz de (A. Mangerich) alexander.buerkle@uni-konstanz.de (A. Bürkle).
}

dent of DNA damage, PARP-1 can be activated by phosphorylated ERK2 (Cohen-Armon et al., 2007). The resulting posttranslational modification of nuclear proteins with PAR includes PARP-1 itself (automodification) and other chromatin-associated proteins, such as DNA repair and transcription factors. Apart from covalent modification of proteins, PAR can bind to proteins also in a noncovalent manner (Altmeyer et al., 2009; Fahrer et al, 2007; Gagne et al., 2008; Pleschke et al., 2000; Tao et al., 2009). The formation of PAR is transient, since the polymer is rapidly hydrolyzed by PARP's catabolic counterpart, poly(ADP-ribose) glycohydrolase (PARG) (Min and Wang, 2009). Although Parp $1^{-1-}$ cells exhibit some residual PAR synthesis, due to the action of other poly(ADP-ribose) polymerases, mainly PARP-2, PARP-1 accounts for about $90 \%$ of the overall cellular poly(ADP-ribosyl)ation capacity upon genotoxic stress (Shieh et al., 1998).

The variety of PARP- 1 target proteins and of PAR-binding proteins reflects the diversity of cellular functions of PARP-1, which cover the areas of genomic maintenance, cell cycle control, 
chromatin remodeling, gene transcription, and regulation of cell death (Sclireiber et al., 2006).

The diverse functions of PARP-1 on the cellular level are reflected in its contribution to multiple physiological and pathophysiological conditions at the organismal level. Much information about the function of PARP-1 was obtained from three independently generated knock-out mouse models (de Murcia et al., 1997; Masutani et al., 1999; Wang et al., 1995). Parp $-1^{-1}$ mice were hypersensitive both to alkylating agents or ionizing radiation, and Parp $1^{-1}$ cells displayed increased spontaneous genomic instability (d'Adda di Fagagna et al., 1999; Shall and de Murcia, 2000). Rather unexpectedly, work on Parp- $1^{-1-}$ mice revealed that PARP-1 participates in several inflammationassociated pathophysiological conditions. Thus, Parp-1 $1^{-1-}$ animals were protected from experimentally induced arthritis, type I diabetes mellitus, ischemic infarction, Parkinson's disease, as well as septic or hemorrhagic shock (Beneke, 2008; Shall and de Murcia, 2000).

At least two mechanisms have been proposed to be responsible for the development of PARP-1-related pathologies: Firstly, PARP-1 can be overactivated by severe DNA damage in response to an initial pathological insult. This could lead to NAD ${ }^{+}$and ATP depletion causing necrosis and further tissue damage due to inflammation (Heeres and Hergenrother, 2007). Secondly, PARP-1 was shown to act as a coactivator of the pro-inflammatory transcription factor NF-kB (Hassa et al., 2001; Hassa et al., 2005; Stilmann et al, 2009).

The double-edged role of PARP-1 as a caretaker of genomic stability on the one hand and as a cell death and inflammation mediator on the other hand is also reflected in its role in aging and longevity (Beneke and Bürkle, 2007). The recent finding that Parp$1^{-1-}$ mice age moderately faster compared to wild-type (wt) animals is in accordance with the view that PARP-1 counteracts the aging process (Piskunova et al., 2008). Supporting this notion, PARP-1 was shown to act as a tumor suppressor gene in various studies. Thus, PARP-1 deficiency enhances age-related as well as experimentally induced carcinogenesis (Piskunova et al., 2008; Tong et al., 2001). Furthermore, poly(ADP-ribosyl)ation capacities of 13 mammalian species strongly correlate with their maximum life span (Grube and Bïrkle, 1992). Those variations in poly(ADPribosyl)ation capacity were not due to different PARP-1 expression levels, but presumably due to interspecies differences in the intrinsic protein sequence itself. Thus, recombinant human PARP-1 exhibits a significantly higher capacity for PAR automodification than its rodent orthologue (Beneke et al., 2000; Beneke et al., 2010). Additionally, poly(ADP-ribosyl)ation capacity declines with age in humans as well as rodents, and centenarians display significantly higher poly(ADP-ribosyl)ation capacities than those of the average population (Chevanne et al., 2007; Grube and Bürkle, 1992; Muiras et al., 1998). Further implication of PARP 1 in aging/longevity is indicated by molecular studies showing that PARP- 1 is involved in the maintenance of telomere length (Beneke et al., 2008; d'Adda di Fagagna et al., 1999) and in the regulation of various proteins which are associated with aging including WRN, p53, ATM, and DNA-PK (Aguilar Quesada et al., 2007; Haince et al., 2007; Kanai et al., 2007; Ruscetti et al., 1998; von Kobbe et al., 2003; von Kobbe et al., 2004).

On the other hand, PARP-1 competes with the family of type III histone-deacetylases of sirtuins, which have been identified as longevity proteins in various species, for the same substrate, i.e., $\mathrm{NAD}^{+}$(El Ramy et al., 2009; Kolthur-Seetharam et al., 2006; Pillai et al., 2005; Rajamohan et al., 2009). Based on this antagonistic interplay between PARP-1 and sirtuins, and the role of PARP-1 as a cell death and inflammation mediator, PARP- 1 was also postulated as an aging- and tumor-promoting factor (Aguilar-Quesada et al., 2007; Zhang, 2003). In support of this concept, PARP inhibition or genetic ablation improved aging-associated cardiac and vascular dysfunctions and reduced susceptibility to experimentally induced skin carcinogenesis (Martin-Oliva et al., 2004; Radovits et al., 2007; von Lukowicz et al, 2008). Moreover, gene expression of a whole range of pro-inflammatory cytokines, adhesion molecules, and enzymes (e.g., iNOS) are downregulated in Parp- $1^{-1-}$ mice and cells (Hassa and Hottiger, 2002). These findings led to the hypothesis that under certain conditions PARP-1 contributes to so-called 'inflammaging', i.e, an increased inflammatory burden with advanced age that drives physiological aging (De Martinis et al. 2005).

Here, we report the phenotypic characterization of a novel PARP-1 mouse model, termed $h P A R P-1$ mice. These mice harbor an ectopic integration of the full-length $h P A R^{p}-1$ coding sequence, which is transcriptionally controlled by a mParp- 1 promoter (Mangerich et al., 2009). During the generation of $h$ PARP-1 mice, the integration of the targeting construct followed the mechanism of ectopic gene targeting; that is, in addition to the ectopic integration of hPARP-1 on murine chromosome 1 , mParp-1flanking sequences were copied by endogenous DNA polymerases resulting in duplication of the mParp-1-flanking loci. As a result, homozygous mutant mice used in the current study comprised two copies of endogenous mParp-1 plus two copies of heterologous hPARP-1 (Mangerich et al., 2009). Our phenotypic analyses revealed a multifaceted pathological phenotype of $h P A R P-1$ mice. Mutant mice exhibited impaired survival rates and developed several inflammation and age-related pathologies prematurely and at higher incidence compared to wt controls. Moreover, $h P A R P$ 1 mice showed a shift in tumor spectrum. The findings that DNA strand break repair was delayed in splenocytes of hPARP-1 mice and that gene expression of pro-inflammatory cytokines TNF- $\alpha$, IL1 , and IL- 6 was dysregulated in hPARP-1 mice provide a mechanistic basis for the observed phenotype of hPARP-1 mice.

\section{Material and methods}

2.1. Generation of mice, animal husbandry, and genotyping

Generation of human PARP-1 mice has been described previously (Mangerich et. al., 2009). All experiments were approved by the competent local veterinan authorities (Regiemugsprüsidium Freiburg, Germany). Mice were housed in the central animal care facility of the University of Konstanz, in individually ventilated cages (VC) in a $12 \mathrm{~h}$ light $/ 12 \mathrm{~h}$ dark cycle (light on at $7 \mathrm{AM}$ ) according to national guidelines. Animal handling was performed under a laminar flow hood. Pathogen and parasite-free status was verified periodically by microbiological and serological health monitoring in accordance with FELASA recommendations performed by MFD Diagnostics (Wendelsheim, Germany). Animals were fed ad libitum on a normal fat diet (No. 3800; Kliba Nafag, Kaiseraugst, Switzerland) and moved to freshly prepared cages every other week. Offspring was weaned at the age of about four weeks, sexes separated, and mutant mice housed with littermates. Euthanasia was carried out by $\mathrm{CO}_{2}$ inhalation. Mice of the developmental and aging studies were on a mixed genetic background ( $\mathrm{B} 6 ; 129 \mathrm{P} 20 \mathrm{aHsd}$ ) obtained by intercrossing

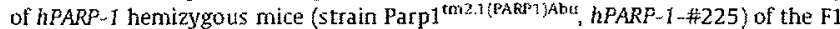
generation to obtain wt littermate controls and genetically modified animals carrying either one or two alleles of $h P A R P-1$. Mice used for glucose tolerance test, DNA repair measurements, and PARP activity measurements were congenic on a C57BL 6 background. Human PARP-1 hemizygous breeding pairs were used to obtain hPARP- 1 homozygous and wt lines. Genotyping by conventional and quantitative PCR was performed as described previously (Mangerich et al., 2009).

\section{RNA isolation and $R T-P C R$}

Mouse spleens were removed immediately after euthanasia of mice and immediately submerged in ten volumes of RNAlater RNA stabilization reagent (Qiagen, Hikden, Germany). Total RNA was isolated using the RNeasy Mini kit (Qiagen, Hilden, Germany). For this purpose, 15-20 mg of mouse splenic tissue was homogenized on ice with a glass douncer in $600 \mu 1$ of the lysis buffer provided Subsequent steps were performed according to the manufacturer's instructions. Patential contaminations with genomic DNA were eliminated using the RNase-Free DNase kit (Oiagen, Hilden, Germany). RNA was eluted with $50 \mu l$ of RNase-free water, concentration and purity determined by photometric measurements of absorbance at $260 \mathrm{~nm}$ and $280 \mathrm{~nm}$. Samples were stored at $-80^{\circ} \mathrm{C}$ until further use. Reverse-transcriptase (RT) PCR was performed with the isolated total RNA to obtain complementary DNA (cDNA) using the iscript cDNA Synthesis kit (Bio-Rad, Munich 
Germany) according to manufacturer's instructions. CDNA was amplified using the iQ SYBR Green Supermix (Bio-Rad, Munich, Germany) according to the manufacturer's instructions with the following primer sets: TNF- $\alpha$-fwd, ccac cacgctcttctgtcta; TNF- $\alpha$-rev, agggtctgggccatagaact; Il-6-fwd, gagcccaccaagaacgatag; 11-6-rev, tcagtcccaagaaggcaact; II-1 $\alpha-\mathrm{fwd}$; Il-1 $\alpha-\mathrm{rev}$, gcaacgggaagattctgaag; Hprt-fwd, aagcttgctggtgaaagga; Hprt-rev, caagggcatatccaacaaca; Tbp-fwd cagcttccaccttatgctc; Tbp-rev, ccgtaaggcatcattggact; Sdha-fwd, aacactggaggaagcacacc; Sdha-rev, gcacagtcagcctcattcad. Primers of all primer pairs were designed to bind in different exons to exclude amplification of any residual contaminating genomic DNA. Following completion of each run melt curve analyses were performed to ensure specificity of the amplicons obtained. As reference combination of Hprt, Tbp, and Sdha expression was used and data was analyzed using iQ5 Optical System software (Bio-Rad, Munich, Germany). All measurements were performed in technical triplicates.

\subsection{Western blot analysis}

Freshly removed tissue, snap-frozen in liquid nitrogen, was lysed on ice by homogenizing with a douncer in modified high-salt RPA buffer ( $9 \mathrm{ml} / \mathrm{g}$ tissue) containing $50 \mathrm{mM}$ Tris $\mathrm{HCl}(\mathrm{pH} 7.4), 500 \mathrm{mM} \mathrm{NaCl}, 1 \%$ (wiv) Triton-X-100, $0.1 \%$ SDS, $1 \%(w / v)$ sodium-deoxycholate, and Complete protease inhibitor mix (Roche Diagnostics, Mannhein, Germany). Then insoluble organ and cell debris was pelleted for $15 \mathrm{~min}$ at $4000 \times \mathrm{g}$ and $4{ }^{\circ} \mathrm{C}$, protein concentrations were determined using the BCA protein assay (Thermo Fisher Scientific, Ulm, Germany), and diluted in $1.5 \times$ high-urea lysis buffer containing $62.5 \mathrm{mM}$ Tris $-\mathrm{HCl}(\mathrm{pH} 6.8) 6 \mathrm{M}$ urea, $5 \%$ (v/v) 2-mercaptoethanol, $10 \%$ (v/v) glycerol 2\%(w/v) SDS, and $0.003 \%$ bromophenol blue. Forty micrograms of protein was used for Western blot analyses. Whole-tissue lysates were separated on $8 \%$ polyacrylamide gels and proteins were transferred onto Hybond-ECL nitrocellulose membrane (GE Healthcare, Freiburg, Germany) for $2 \mathrm{~h}$ at $300 \mathrm{~mA}$ using a wet-blotting device. Membranes were blocked for $1 \mathrm{~h}$ in $5 \%$ (w/v) dry-milk diluted in $10 \mathrm{mM}$ Tris- $\mathrm{HCl}(\mathrm{pH} 8.0), 150 \mathrm{mM} \mathrm{NaCl}$, and $0.05 \%$ ( $/ \mathrm{v}$ ) Tween 20 , and incubated overnight at $4{ }^{\circ} \mathrm{C}$ with the following primary antibodies: monoclonal CII10 (PARP-1-specific), monoclonal F23 (human-PARP-1-specific) and polyclonal antiserum 4595 (murine-PARP-1-specific) (Mangerich et al., 2009) Peroxidase-coupled goat-anti-mouse or goat-anti-rabbit secondary antibodies (Dako, Glostrup, Denmark) were used for chemiluminescent detection.

\subsection{NAD-cycling assay}

To determine $\mathrm{NAD}^{+}$levels, splenocytes were isolated as ex vivo single-cel suspensions from mouse tissue. All steps were performed on ice or at $4^{\circ} \mathrm{C}$ spleens were removed immediately from sacrificed mice, cut into pieces, placed in a cell strainer ( $100 \mu \mathrm{m}$ pore-width; Becton-Dickinson, Heideberg, Germany) covered with $1 \mathrm{ml}$ of DMEM, and passed through the cell strainet into a 6 -cm Petri dish using the plunger end of a 5-ml syringe. The cell strainer was rinsed with $5 \mathrm{ml}$ of DMEM Then, cells were centrifuged at $800 \times g$ for $3 \mathrm{~min}$, the supernatant was discarded and the cell pellet resuspended in $1 \mathrm{ml}$ lysis buffer ( $150 \mathrm{mM} \mathrm{NH}_{4} \mathrm{Cl}_{1} 10 \mathrm{mM} \mathrm{KHCO}_{3}$ $120 \mu \mathrm{M}$ EDTA) and incubated for $5 \mathrm{~min}$ on ice to lyse ery throcytes. Thereafter, $9 \mathrm{ml}$ of DMEM was added, cells pelleted, and again resuspended in 3 ml DMEM. NAD levels were determined as described previously using an enzymatic cycling assay modified from (Bernofsky and Swan, 1973; Jacobson and Jacobson, 1976). Briefly, ES cells or splenocytes were harvested and $1 \times 10^{5}$ cells were resuspended in $500 \mu$ PBS and inmediately placed on ice. Subsequently, $24 \mu$ l of perchloric acid (11.63 M) was added, reaction mixtures were incubated for $15 \mathrm{~min}$ on ice, and centrifuged for 10 min at $1500 \times g$. Then the supernatant was mixed with $350 \mu$ of $0.33 \mathrm{M} \mathrm{K}_{2} \mathrm{HPO}_{4}$ (pH 7.5), centrifuged, and frozen at $-20^{\circ} \mathrm{C}$. After thawing and centrifugation, $40-\mu$ samples were mixed with $160 \mu \mathrm{I}$ of buffer $\mathrm{A}\left(0.25 \mathrm{M} \mathrm{H}_{3} \mathrm{PO}_{4}, 0.5 \mathrm{M} \mathrm{NaOH}\right)$ and $100 \mathrm{\mu l}$ of buffer $\mathrm{B}[0.34 \mathrm{M}$ bicine- $\mathrm{NaOH}(\mathrm{pH} 8.0), 2.9 \mathrm{mg} / \mathrm{ml} \mathrm{BSA}, 14.3 \mathrm{mM}$ EDTA $1.4 \mathrm{mM} M T$, $1.7 \mathrm{M} \mathrm{EtOH}, 5.7 \mathrm{mM}$ phenazine ethosulfate, $0.14 \mathrm{mg} / \mathrm{ml} \mathrm{ADH]}$. After a 30 min incubation period at $30^{\circ} \mathrm{C}$, absorption was measured at $550 \mathrm{~nm}$ (with $690 \mathrm{~nm}$ as a reference wavelengthi) in a 96-well-plate ELSA reader.

\subsection{Assessment of poly(ADP-ribosyl)ation copacity}

Poly(ADP-ribosyl)ation capacity was assessed by treating freshly isolated splenocytes with $10 \mathrm{mM} \mathrm{H}_{2} \mathrm{O}_{2}$ in $\mathrm{PBS}$ supplemented with $2 \mathrm{mM} \mathrm{Morl}_{2}$ (PBS$\mathrm{MgCl}_{2}$ ) ar, as control, in PBS- $\mathrm{MgCl}_{2}$ only, followed by incubation af $37^{\circ} \mathrm{C}$ for $5 \mathrm{~min}$. Afterwards cells were pelleted, snap-frozen in liquid nitrogen, and prepared for Western blot analysis as described above. A total number of $1 \times 10^{6}$ cell equivalents was loaded per lane and after SDS.PAGE and Western blotting the level of poly(ADP-ribosyl)ation of proteins was assessed by immunos taining with anti-PAR primary antibody 10H (Kawamitsu et al., 1984).

2.6. Measurement of DNA repair by automated furimetric detection of alkaline DNA unwinding (FADU)

Experiments were performed on freshly isolated splenocytes after $1 \mathrm{~h}$ of ex vivo cultivation in DMEM supplemented with 10\% FCS. Measurements were performed as described recently (Moreno-Villanueva et al., 2009) using a slightly modified protocol with a DNA unwinding time of $30 \mathrm{~min}$.

\subsection{Pathology and histology}

The abdominal cavity and thorax of sacrificed mice were completely opened and tissues fixed by submerging the whole carcass in at least ten volumes of $10 \%$ formalin. Histopathological analyses of the animals were performed according to standard procedures. An indirect immunoperoxidase method was used to determine insulin-secreting cells in pancreatic tissue as described previously (Herbach et al., 2005).

\subsection{Grading of histopothological lesions}

All lesions were graded as published previously, with madifications (Ikeno et al. 2003: Treuting et al, 2008 3. Eriefly, neoplastic lesions were graded on a scale from 1 to 4 based on their size and distribution (metastasis). Grade 1 lesions included small ( $<3 \mathrm{~mm}$ ), focal tumors at the primary site without observably affecting the surrounding tissue. Grade 2 lesions included larger tumors with multiple foci within the primary site or metastases to one other organ and observable changes of the surrounding parenchyma (compression or necrosis). Grade 3 lesions included metastases to 2-3 other organs. Grade 4 lesions included tumors with metastases to 4 of more organs. Depending on the differentiation status of lymphomas lymphomas were distinguished in low-grade or high-grade. Since only high-grade lymphomas were detected in our mouse cohor ts, lymphomas were graded in every case as grade 3 lesions. Tumor burden was calculated as the sum of the individual tumor grades within a mouse. Cumulative tumor burden was calculated as the average sum of tumor burdens in cohorts of each genotype at a given time point Non-reoplastic lesions were graded according to their severity on a scale ranging from 0 to 4 with 0 as normal, 1 as mild, 2 as moderate, 3 as strong. and 4 as severe pathological alterations. Disease burdens of individual mice were calculated as the sum of the individual disease grades and tumor grades within a mouse. Cumulative disease burdens were calculated as the average sum of overall or disease-specific burdens in cohorts of each genotype at a given time point.

\subsection{Xray examination}

$\mathrm{X}$-ray analysis was performed with a medical X-ray apparatus (Siemens, Munich Germany) using an intensity of $55 \mathrm{kV}, 8 \mathrm{nA}$ for $1.6 \mathrm{~s}$ according to the manufacturer's instructions.

\subsection{Hair regrowth analysis}

Hair regrowth analysis was performed as described previously (Harrison and Archer, 1988; Tyner et al, 2002). For this purpose, an area of $4 \mathrm{~cm}^{2}$ was shaved on the dorsal surface of age-matched wh and $h P A R P-l$ mice using a stencil and an electric razor. Hair regrowth was assessed under blind-testing conditions 20 days after shaving and expressed as percentage of area covered with regrown hair.

\subsection{Measurement of plasma lipids}

Blood was taken after $4 \mathrm{~h}$ of daytime fasting. Plasma triglycerides and cholesterol were determined using commercial kits (Roche) which were adapted to microtitet plates. Lip oproteins of $200 \mu \mathrm{l}$ plasma samples were separ ated by fast protein liquid chromatography (FPLC) gel filtration on a superose 6 column (Amersham-Biosciences), and cholesterol and trigiycerides were determined in each fration.

\subsection{Glucose tolerance test}

Glucose tolerance was tested based on a protocol and suggestions reported previously (Andrikopoulos et al., 2008). In brief, mice were deprived of food at 7:30 AM for $6 h_{t}$ at which time basal blood glucose levels were determined from tai vein blood using an One Touch Ultra glucometer (LifeScan, Neckargemünd Germany) according to the manufacturer's instructions. Thereafter, mice were injected intraperitoneally with $2 \mathrm{mg}$ glucose per gram body weight of a $100 \mathrm{~g} / \mathrm{l}$ glucose solution (Sigma-Aldrich, Steinheim, Germany), and blood glucose level were determined at time points indicated. Ten female and twelve male mice were used for analyses. In the group of mutant male mice two values were identified as outliers by plotting of Tukey whiskers followed by using the Grubb's outlier test (5uppl. Fig. 4). In order to avoid outlier artifacts we excluded these two values from our data set.

\subsection{Mecsurement of hemoglobin AIC}

Hemoglobin $A 1 C$ is a subtype of hemoglobin $A$, which has bound glucose in a non-enzymatic reaction (glycation). Glycation is irreversible and can only be eliminated by degradation of erythrocytes. As the amount of hemoglobin Alc correlates with the degree and length of hyperglycemic conditions, it is comnonly used as a diagnostic indicator for hyperglycemia in humans as well as rodents (Zhao et al., 2007). The percentage of hemoglobin A1C was determined by tsing the A1CNow Hemoglobin test (Bayer Healthcare, Stnnyvale, USA) according to the manufacturer's instructions. 


\subsection{Weight analysis}

Mice were weighed weekly up to the age of four weeks and subsequently every other week

\subsection{Hematology}

For hematologic analyses about $100 \mu$ blood was taken retro-orbitally and supplemented with $5 \mu 10.5 \mathrm{M}$ EDTA (pH 8.0). Analyses of blood samples were performed using a ScilVet abc fully automatic counter (Scil Animal Care Company Viernheim, Germany) with settings specified for mouse hematological parameters.

\subsection{Statistics}

Statistical analyses were performed using GraphPad Prism software and data expressed as means \pm SEM. Two independent data sets were compared with the Student's $t$-test (unpaired, wo-tailed) or Mann-whitney tes (two-tailed) as indicated. Two-way ANOVA test was applied as indicated, Statistical analyses of Kaplan-Meier survival curves were performed using the Log-rank test and the Gehan-BreslowWilcoxon test. Maximum lifespan was determined as the time point at which $90^{\circ}$ of mice have died. Correlation data were analyzed using a linear regression curve fit. $P$ values $<0.05$ were considered statistically significant, $P$ values $<0.1$ as statistical trends.

\section{Results}

Previously, we demonstrated that hPARP-1 has a significantly higher in vitro poly(ADP-ribosyl)ation capacity compared to its rodent orthologue (Beneke et al., 2000; Beneke et al., 2010). Based on the above, we intend to study PARP-1 hypermorphy in vivo, and therefore we recently generated a mouse model with ectopic expression of hPARP-1 which is transcriptionally controlled by the mParp-1 promoter (Mangerich et al., 2009). Here, we provide a detailed phenotypic characterization of those mice.

\subsection{Expression analyses in hPARP-1 mice}

To analyze PARP-1 expression in vivo, several organs were screened for mPARP-1 expression by Western blot analysis of whole-tissue extracts. High PARP-1 expression levels were detected in pancreas, thymus, spleen, testis, and uterus. Moderate PARP-1 expression was detected in brain, heart, kidney, and lung, whereas low or no PARP-1 expression was detectable in intestine (Fig. 1). In accordance with the fact that transgenic hPARP-1 expression is controlled by $M P a r p-1$ promoter sequences, expression of hPARP-1 in mutant mice followed the same expression pattern as observed with endogenous MPARP-1 (Fig. 1).

To analyze MPARP- 1 and ectopic hPARP- 1 expression in greater detail, we performed Western blot analyses of spleen lysates of wt mice as well as hemizygous $(1 \times h P A R P-1)$ and homozygous $(2 \times h P A R P-1)$ mutant mice using PARP-1 species-specific antibodies. Western blot results demonstrated moderate overexpression of total PARP-1 in an hPARP-1-gene-dose-dependent manner (Fig. 2). Moreover, hPARP-1 mice displayed expression of fulllength hPARP-1 in an hPARP-1-gene-dose-dependent manner (Fig. 2). Intriguingly, mPARP-1 expression was inversely correlated to hPARP-1 expression (Fig. 2). No additional signals from potentially truncated murine or human PARP-1 were detectable, indicating that both gene loci were fully functional.

In conclusion, mutant mice show gene-dose-dependent expression of the hPARP-1 transgene which accounted for about $50 \%$ of overall PARP-1 expression in the homozygous mutant animals.

\subsection{Analysis of poly(ADP-ribose) metabolism}

In order to test poly(ADP-ribosyl)ation capacity in the hPARP-1 expressing cells, we determined intracellular levels of the PARP-1 substrate $\mathrm{NAD}^{+}$and assessed poly(ADP-ribosyl)ation capacity. In agreement with previous in vitro results, showing higher poly(ADP-ribosyl)ation capacity of hPARP-1 compared to its rodent

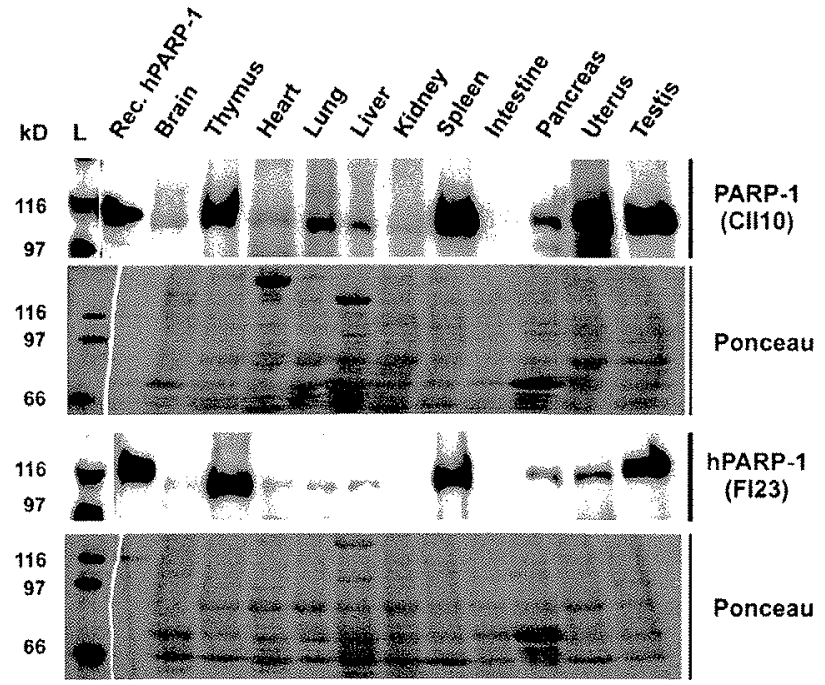

Fig. 1. Expression analysis of PARP- 1 in different trgans of wild-type and hPARP-1 mice. Analysis of mPARP-1 and hPARP-1 expression in different tissues of wt (top antibody CI110) and homozygous mutant mice (bottom, antibody FI23). Western blot analys is of whole-tissue lysates. Recombinant (rec) hPARP-1 $(200 \mathrm{ng})$ served as a positive control. Membranes were probed either with the general-PARP-1 antibody CI1 10 or hPARP-1-specific antibody FI23, respectively. Ponceats staining of membranes served as loading control. L, molecular size ladder.

orthologue (Beneke et al., 2000; Beneke et al., 2010), hPARP-1expressing ES cells exhibit about 30\% lower $\mathrm{NAD}^{+}$levels compared to wt controls (Suppl. Fig. 1). By contrast, we detected no significant differences in $\mathrm{NAD}^{+}$levels in freshly isolated splenocytes from mutant compared to wt mice. Furthermore, no differences in poly(ADP-ribosyl)ation capacity were detectable in splenocytes after challenging the cells with $10 \mathrm{mM} \mathrm{H}_{2} \mathrm{O}_{2}$.

\subsection{Analyses of postnatal development}

Human PARP-1 mice are viable and fertile. No differences in litter sizes or sex ratio were detected (Mangerich et al., 2009). Moreover, the majority of mutant mice developed apparently normally. However, spontaneous deaths were observed in the group of mutant mice as early as one month of age, whereas the first deaths within the cohort of wt littermates occurred at nine months. During the establishment of the new mouse lines, we sporadically observed severe adiposity with body weights over $60 \mathrm{~g}$ at an age as early as six months within the mutant cohort. A maximum body weight of $68.4 \mathrm{~g}$ was determined in the case of a hemizygous mutant female at the age of ten months (data not shown). These incidental findings prompted us to evaluate any potential changes in growth and metabolism of hPARP-1 mice. Mutant mice of both sexes were up to $10 \%$ heavier from week four onwards (Fig. 3), without showing any differences in body length (Suppl. Table 1). The effect was more pronounced in hPARP-1 hemizygotes compared to hPARP-1 homozygotes. By the age of three months, wt females and males averaged $24.9 \mathrm{~g}$ and $31.2 \mathrm{~g}$ in body weight, whereas hPARP-1 hemizygous females and males weighed $27.5 \mathrm{~g}$ and $34.4 \mathrm{~g}$, and hPARP-1 homozygous females and males weighed $25.6 \mathrm{~g}$ and $33.6 \mathrm{~g}$, respectively. To further analyze possible causes of the higher body weights of mutant mice and to analyze these mice with respect to any developmental pathology, detailed organ weight and histopathological analyses were performed in wt and homozygous mutant mice at the age of three months. This study revealed increased organ weights for heart $(+27 \%)$, pancreas $(+45 \%)$, and spleen $(+78 \%)$ (Suppl. Table 1 ). Sporadic adiposity was detected in the group of mutant mice, but 

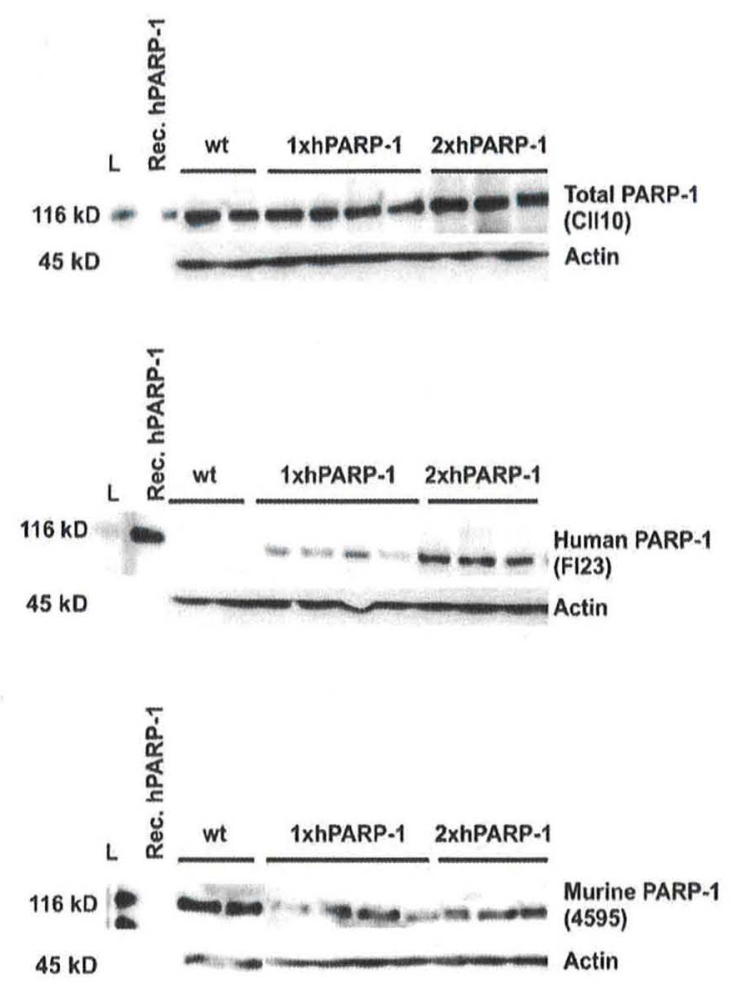
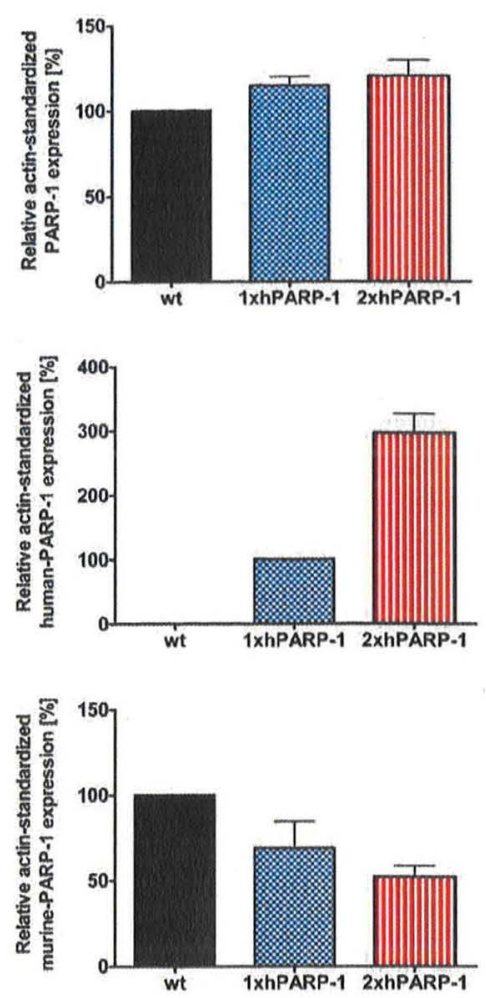

Fig. 2. Semi-quantitative expression analysis of PARP-1 in wild-type and $h P A R P-1$ mice. Left: Western blot analyses of whole-spleen lysates prepared from of two wild-type (wt), four hemizygous mutant ( $1 \times h P A R P-1)$, and three homozygous mutant ( $2 \times h P A R P-1)$ mice analyzed with the general-PARP-1-specific antibody CII10, with the hPARP-1specific antibody FI23, and with the mPARP-1-specific antibody '4595'. Recombinant (rec.) hPARP-1 (125 ng) served as control. Detection of actin served as a loading control and for standardization. Right: Densitometric analyses of corresponding blots (data from three individual blots each). Means \pm SEM. L, molecular size ladder.

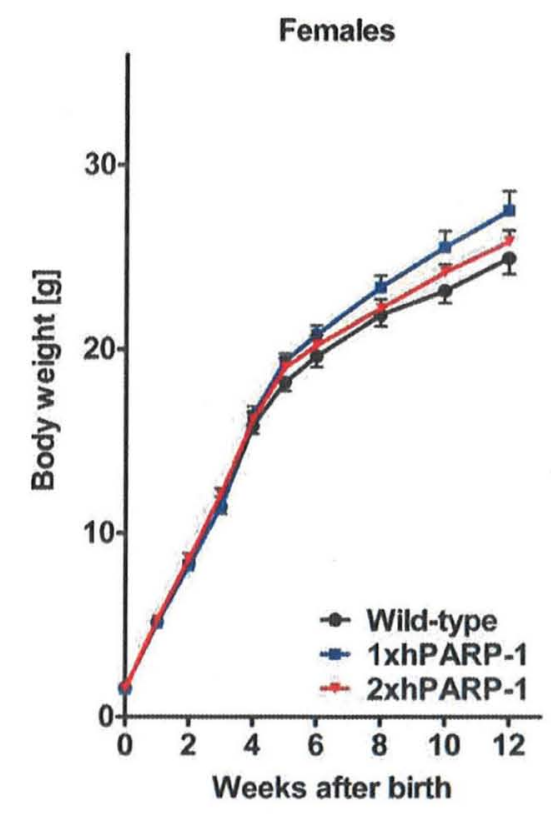

\begin{tabular}{|l|c|}
\hline Wt vs 1xhPARP-1 & $P<0.001$ \\
\hline Wt vs 2xhPARP-1 & $P<0.05$ \\
\hline
\end{tabular}

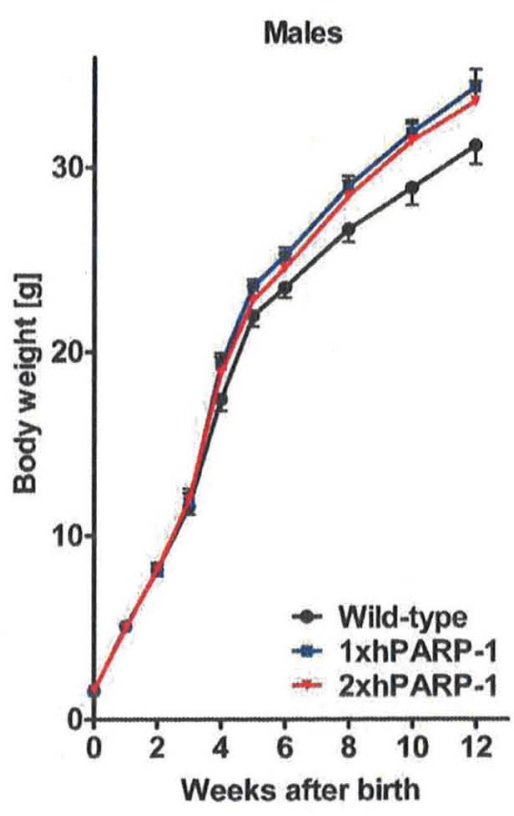

\begin{tabular}{|l|l|}
\hline Wt vs 1xhPARP-1 & $P<0.001$ \\
\hline Wt vs 2xhPARP-1 & $P<0.01$ \\
\hline
\end{tabular}

Fig. 3. Body weight of wt and mutant mice as a function of age. Shown are postnatal body weights of wild-type (wt), hemizygous mutant ( $1 \times h$ PARP -1 ), and homozygous mutant ( $2 \times h P A R P-1)$ mice. Statistical evaluation was performed using two-way ANOVA. $n>7$, means \pm SEM. 
none in that of the wt littermates (Suppl. Fig. 2A). This phenotype was also accompanied by adiposity-related pathologies such as fatty liver disease (Suppl. Fig. 2C-D). The finding that overall body weights correlate significantly with abdominal adipose tissue masses (Suppl. Fig. 2B) suggests that increased body weights of mutant mice are caused at least in part by an increase in adipose tissue mass.

To test if lipid metabolism was generally affected in mutant mice, plasma cholesterol and triglyceride concentrations were determined in non-obese animals and lipoprotein profiles were analyzed by gel filtration chromatography. Our results showed that neither plasma triglyceride nor cholesterol concentrations were significantly different in mutant compared to wt animals. The lipoprotein profiles were similar for all groups (Suppl. Fig. 3A-B).

Since PARP-1 is associated with the development of both type and type II diabetes (Burkart et al., 1999; Pieper et al., 1999; Szabo, 2005: Szabo et al., 2002; Tempera et al., 2005) and since obesity is a primary risk factor for the development of type II diabetes (Kahn et al., 2006; Rosen and Spiegelman, 2006), potential effects on glucose metabolism were studied in hPARP-1 mice. Initial determination of basal blood glucose concentrations of non-fasting twelve-week-old male mice revealed $16 \%$ higher glucose concentrations in hPARP-1 homozygotes compared to wt animals $(P=0.05$, data not shown). Since changes in basal blood glucose concentrations possibly indicate a prediabetic or diabetic condition (Braunwald, 2001), we performed glucose tolerance testing according to recently recommended procedures (Andrikopoulos et al., 2008). While basal fasting blood glucose levels of mutant mice were equal compared to those of wt controls (Fig. 4C), we detected potentially impaired glucose tolerance in the group of mutant males. This effect reached statistical significance after outlier correction of the glucose response curves (Fig. $4 \mathrm{~A}$ and $\mathrm{B}$ and Suppl. Fig. 4). This alteration in glucose metabolic response was gender-specific, since mutant females showed no differences in glucose tolerance compared to wt controls (Fig. 4A and B). Of note, in our setting ( $6 \mathrm{~h}$ fasting, intraperitoneal application of $2 \mathrm{mg} / \mathrm{g}$ glucose, five-month old C57BL/6 mice) we detected highly significant differences in glucose response of wt males compared to wt females. Moreover, basal fasting blood glucose levels were higher in wt males compared to females, although this did not reach statistical significance (Fig. $4 \mathrm{C}$ ). In order to test if mutant males developed a manifest diabetic state we measured hemoglo-

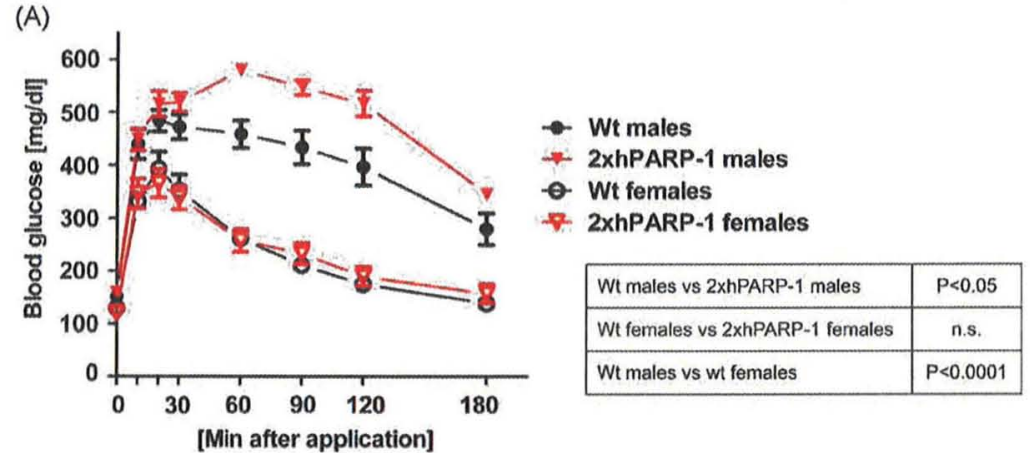

(B)

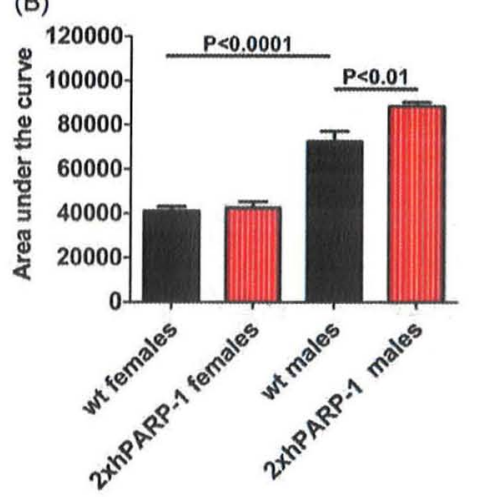

(C)
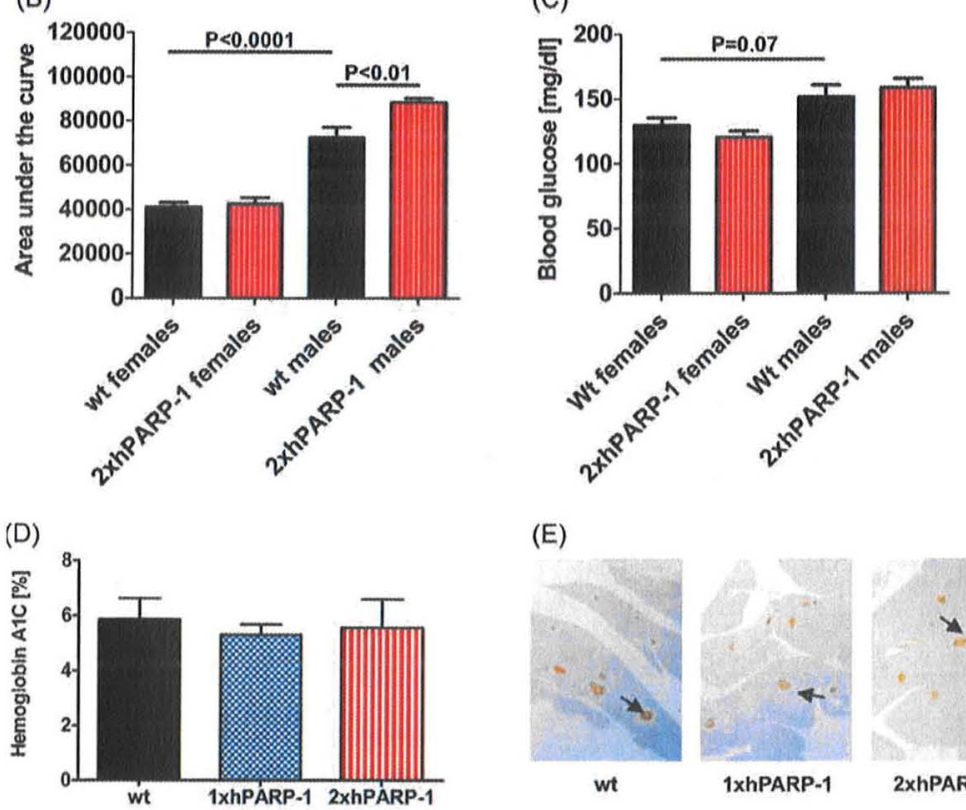

(E)

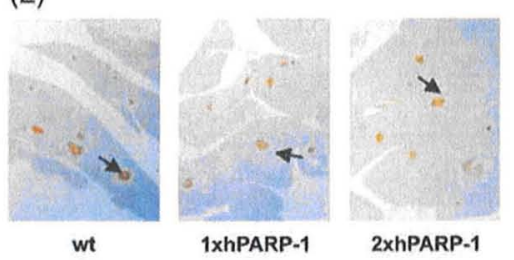

Fig. 4. Analysis of glucose metabolism. (A) Intraperitoneal glucose tolerance test ( $2 \mathrm{mg} / \mathrm{g}$ ) of 5 -month old wild-type (wt) and homozygous mutant ( $2 \times$ hPARP-1) mice after $6 \mathrm{~h}$ of fasting. Statistical evaluation was performed using two-way ANOVA. Females $n=10$, males $n=10-12$, means \pm SEM. (B) Incremental area under the curve. Means \pm SEM from individual response curves are shown. Statistical evaluation was performed using Student's $t$-test. (C) Basal blood glucose levels from mice used in $\mathrm{A}$. Statistical evaluation was performed using Student's $t$-test. (D) Percentage of hemoglobin A1c of total hemoglobin content of one-year old wt, hemizygous mutant (1 $\times h P A R P-1$ ), and homozygous mutant ( $2 \times h$ PARP-1) males. $n=4-6$, means \pm SEM. Statistical evaluation was performed using the Student's $t$-test. (E) Immunostaining for insulin (ar rows) in pancreatic tissue of threemonth old wt and hPARP-1 mice. 
bin A1c levels, which serves as a long-term indicator of blood glucose concentrations, in mice at the age of one year. Fig. 4D shows that the percentage of hemoglobin A1c of the total hemoglobin was equal in wt and mutant males, thereby largely excluding a pronounced diabetic phenotype in the mutant animals. In line with this finding, qualitative immunohistological analysis demonstrated apparently normal insulin content in the $\beta$-cells of the islets of Langerhans in pancreatic tissue (Fig. 4E).

In conclusion, analyses of postnatal development revealed sporadic premature death of mutant animals at the age of young adolescence. Moreover, we detected changes in the metabolic phenotype of mutant mice, such as alteration in body weight and glucose metabolism.

\subsection{Analyses of lifespan of hPARP-1 mice}

Because of the spontaneous cases of death discovered in the group of mutant mice within the first three months of age, we evaluated if hPARP-1 mice exhibit changes in survival rates compared with wt littermates. A survival study comprising $44 \mathrm{wt}, 64$ hemizygous mutant, and 31 homozygous mutant animals was performed. Mutant mice showed significantly impaired survival rates. A similar effect was observed in a second mouse line with ectopic expression of hPARP-1 (Parp1 $1^{\text {tm1.1(PAR- }}$ P1)Abu, hPARP-1-\#113), which had been generated from an independent ES cell clone (Suppl. Fig. 5). Median lifespans of wt, hPARP-1 hemizygous, and hPARP-1 homozygous mice were 686 days, 572 days, and 520 days, respectively (Fig. 5). Maximum lifespans were not significantly different between cohorts of different genotypes. To investigate if this phenotype might be related to segmental premature aging, we assessed hair growth as a potential biomarker of rodent aging (Harrison and Archer, 1988; Tyner et al., 2002) at the age of one and two years. At both ages, hair growth was impaired in the group of mutant mice as compared to their wt littermate controls and reached statistical significance at the age of two years (Fig. 6A). Moreover, it became apparent that spontaneously deceased mice frequently had developed kyphosis (Fig. 6B).

$$
-w t+1 \text { xhPARP-1 }-2 \text { XhPARP-1 }
$$
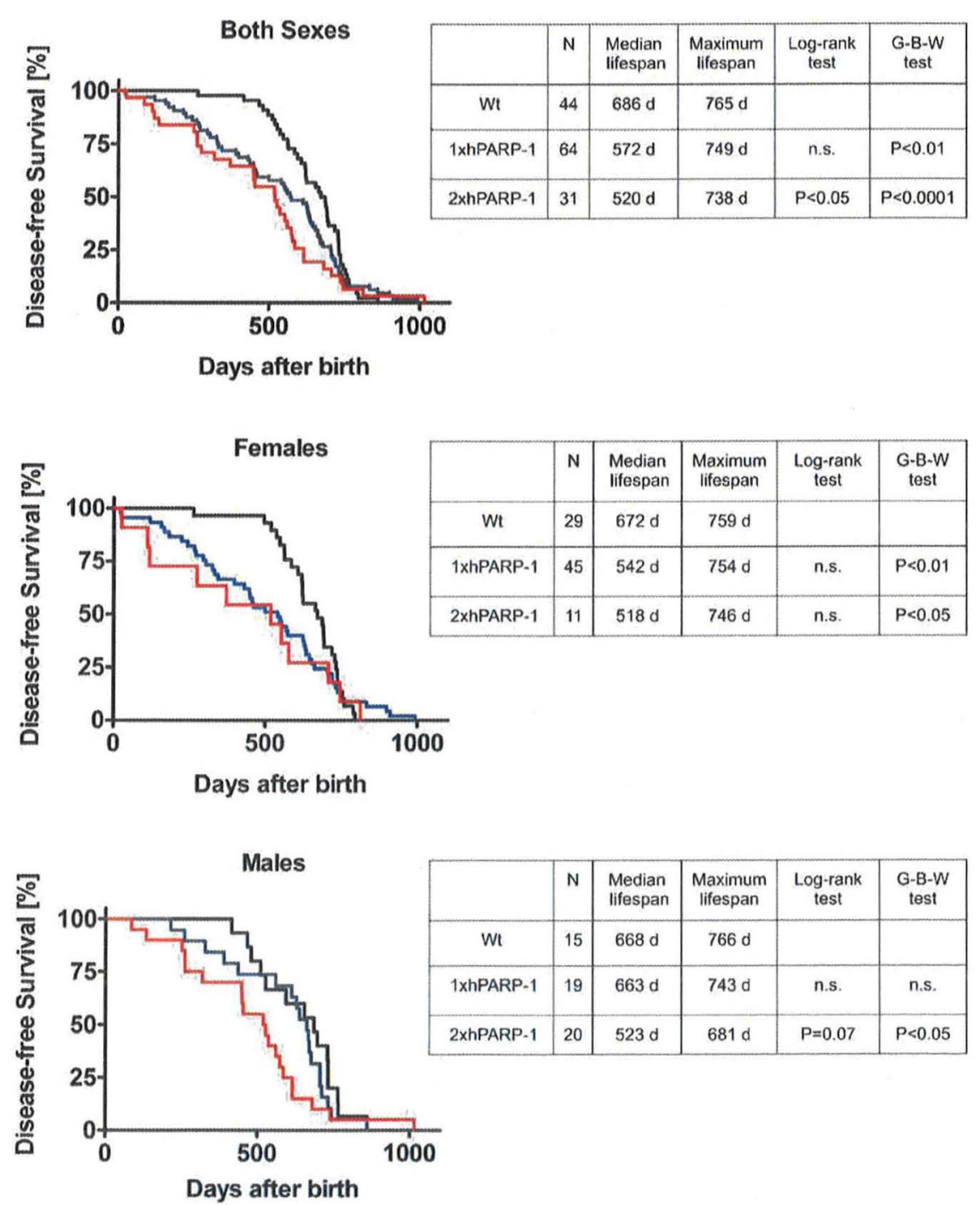

Fig. 5. Kaplan-Meier plots of survival. Animals deceased spontaneously or moribund animals were sacrificed upon veterinary advice. Statistical analyses were performed using Log-rank test and Gehan-Breslow-Wilcoxon test. 

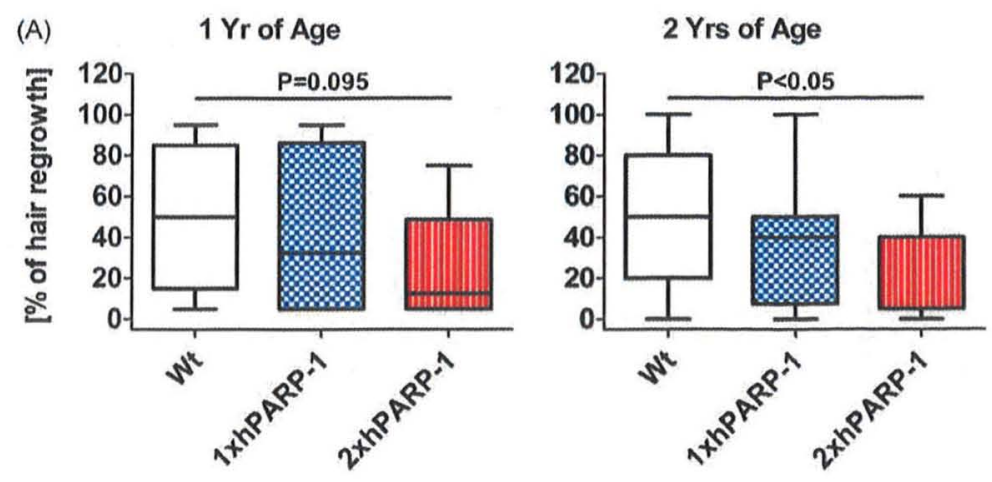

(B)
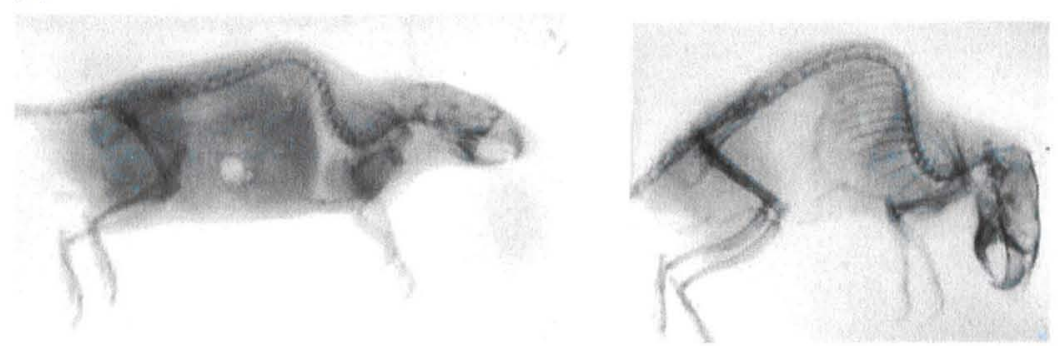

wt male

(3 months)

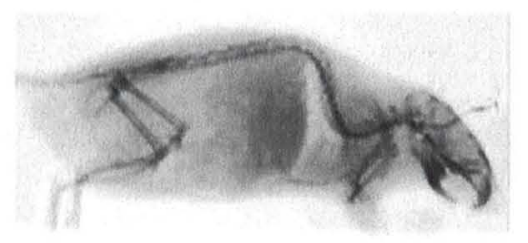

2xhPARP-1 male

(3 months)

wt female

(4 months)

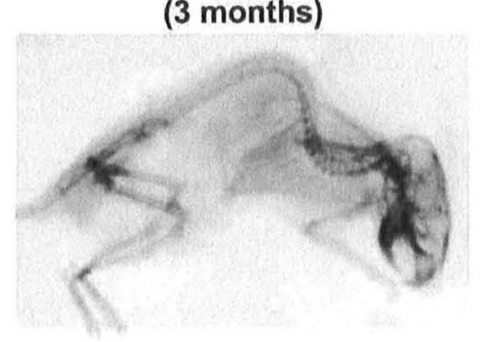

2xhPARP-1 female

(4 months)

Fig. 6. Potential signs of premature aging in $h P A R P-1$ mice. (A) Impaired hair growth in $h P A R P-1$ mice. A 4 -cm ${ }^{2}$ area was shaven on the dorsal skin of mice and hair regrowth was assessed under blind-testing conditions after 20 days as percentage of area covered with regrown hair. Left: Mice of 1 yr of age. Right: Mice of 2 yrs of age. Box-and whisker plot showing medians, interquartile ranges, and tukey whiskers. Statistical evaluation was performed using Mann-Whitney test. (B) Kyphosis detected in moribund or spontaneously deceased $h P A R P-1$ mice. Representative X-ray images of wild-type (wt) and homozygous mutant (2XhPARP-1) mice of ages as indicated.

In summary, hPARP-1 mice showed impaired mean survival rates, accompanied by potential signs of premature aging.

\subsection{Characterization of morbidity in aging hPARP-1 mice}

To investigate the causes for the impaired survival of $h P A R P-1$ mice, moribund or spontaneously deceased animals were studied with respect to the appearance of any abnormalities or pathological alterations compared to wt littermates. Pathological abnormalities (non-neoplastic as well as neoplastic lesions) were graded according to their severity as described in the Section 2. As shown in Fig. 7A, survival rates of the 64 mice included in histopathological analyses paralleled those of the total aging cohort, indicating a representative sub-group of the total cohort. Mutant mice showed significantly impaired survival rates, whereas median and mean disease burdens of individual mice were equal between the different genotypes, thus indicating an earlier onset of diseases in the mutant cohorts (Fig. 7A). While this effect was fairly pronounced for the overall disease burden of cohorts, ie., average sum of grades of non-neoplastic plus neoplastic lesions, and the non-neoplastic disease burden (Fig. 7
B), the situation was more complex when focusing on tumor-related pathologies only. While overall tumor frequencies were slightly higher in the group of homozygous mutant mice compared to wt, no such effect, or even a slightly reverse effect, was observed in the group of hemizygous mutant animals (Fig. 7C).

\subsection{Characterization of non-neoplastic lesions in aging hPARP-1 mice}

All non-neoplastic pathologies detected, such as glomerulopathy, nephritis, hepatitis, myocarditis/cardiac fibrosis, pneumonitis, and dermatitis, developed predominantly at higher frequencies, higher grades, and consistently at earlier time points throughout life in the cohort of mutant animals (Fig. 8 and Suppl. Fig. 6). Strikingly, high-grade (grade 3-4) pathologies, which can be considered as potential causes of death developed already within the first year of life in the group of mutant mice, whereas they were observed in wt mice only at ages higher than 20 months. For example, in the mutant mouse cohorts, grade 4 glomerulopathy was detected by the age of 9 months; grade 3 nephritis by the age of 11 months; grade 4 hepatitis by the age of 11 months, 
(A)

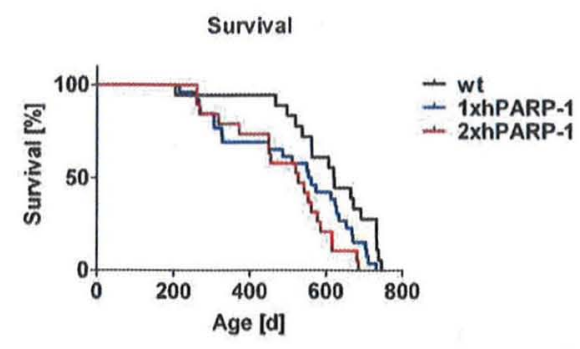

\begin{tabular}{|c|c|c|c|c|c|}
\hline & $\mathrm{N}$ & $\begin{array}{c}\text { Median } \\
\text { lifespan }\end{array}$ & $\begin{array}{c}\text { Maximum } \\
\text { lifespan }\end{array}$ & $\begin{array}{c}\text { Log-rank } \\
\text { test }\end{array}$ & $\begin{array}{c}\text { G-B-W } \\
\text { test }\end{array}$ \\
\hline Wt & 18 & $621 \mathrm{~d}$ & $738 \mathrm{~d}$ & & \\
\hline 1xhPARP-1 & 26 & $557.5 \mathrm{~d}$ & $707 \mathrm{~d}$ & $\mathrm{P}<0.05$ & $\mathrm{P}=0.08$ \\
\hline 2xhPARP-1 & 20 & $527 \mathrm{~d}$ & $681 \mathrm{~d}$ & $\mathrm{P}<0.01$ & $\mathrm{P}<0.01$ \\
\hline
\end{tabular}

Disease Burden of Individual Mice

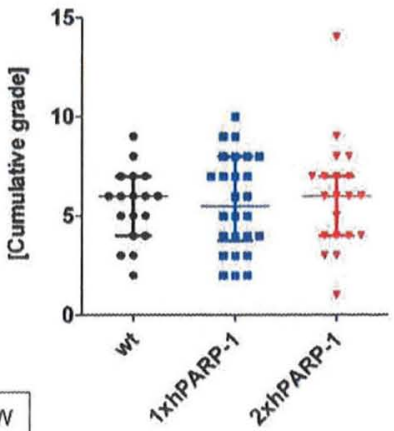

(B)

Cumulative Disease Burden

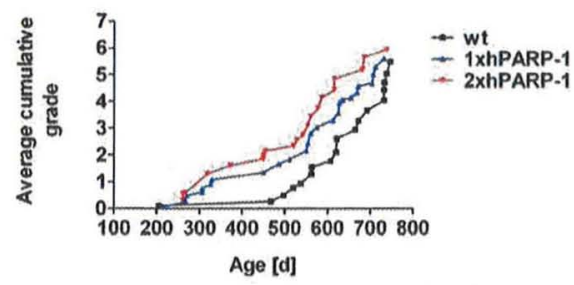

(C)

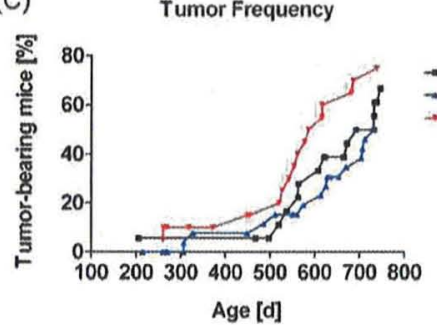

Cumulative Non-neoplastic Disease Burden

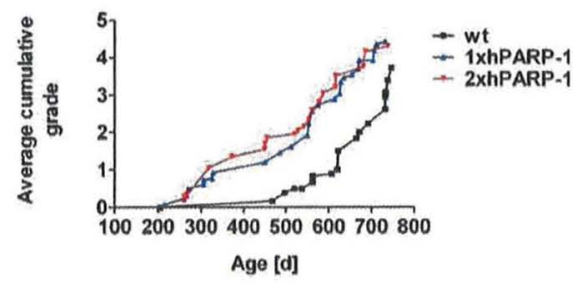

Cumulative Tumor Burden

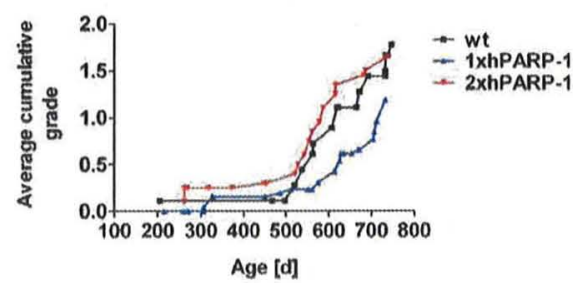

Fig. 7. Overview of histopatholgical analysis of wild-type and hPARP-1 mice. (A) Left: Kaplan-Meier survival plots of mice subjected to histopathological analysis. Animals deceased spontaneously or moribund animals were sacrificed uponveterinary advice. Statistical analyses were performed using Log-rank test and Gehan-Breslow-Wilcoxon test. Right: Disease burdens of individual mice as evaluated by cumulative grade of pathologies. Shown are medians with interquartile ranges. (B) Left: Cumulative disease burdens in cohorts of each genotype as evaluated by the average sum of the individual disease burdens within a mouse. Right: Cumulative non-neoplastic disease burdens in cohorts of each genotype as evaluated by the average sum of the individual non-neoplastic disease burdens within a mouse. (C) Left: Tumor frequencies in cohorts of each genotype subjected to histopathological analysis. Right: Cumulative tumor burdens in cohorts of each genotype as evaluated by the average sum of the tumor burdens of individual mice

grade 3 pneumonitis by the age of 11 months, and grade 3 dermatitis by the age of 9 months (Suppl. Figs. 6-9). Moreover, moderate cardiomyopathy (grade 2) was detected in mutant mice by the age of 11 months, whereas first appearance of disease was detected in wt mice by the age of 21 months. We also observed potential hypertrophy of the islets of Langerhans in four hemizygous mutant (15\%) and two homozygous mutant mice (10\%) (Suppl. Fig. 10). However, this alteration should be interpreted with caution, since no morphometric measurements were conducted. In conclusion, many of the inflammation-related pathologies that naturally occurred in old wt mice developed in mutant mice already at considerably younger ages, at higher frequencies, and with higher severity.

\subsection{Characterization of neoplastic lesions in aging hPARP-1 mice}

The first tumors were observed at the age of 6.8 months in wt (epithelioma) and at the age of 8.7 months in mutant mice (lymphoma). Whereas overall tumor load in moribund mice was similar in wt and mutant mice, differences in the nature of the tumors became apparent (Fig. 9 and Suppl. Fig. 11). About one third of wt mice developed hemangiomas or hemangiosarcomas (first detection at the age of 17.3 months), whereas none of the mutant mice developed this type of neoplasm. In contrast, the incidence of adenomas and carcinomas nearly doubled in the group of homozygous mutant mice, with $28 \%$ of wt and about $50 \%$ of homozygous mutant mice affected. In particular, the incidence of hepatocellular adenomas and carcinomas was increased in the group of mutant mice with about $20 \%$ of homozygous mutant mice developing this type of neoplasm compared with only $6 \%$ of wt mice (Suppl. Fig. 12). First onset of this type of neoplasm was detected at 24.7 months of age in wt mice, whereas at 18.7 months of age in mutant mice. Of note, three out of seven of the detected hepatocellular carcinomas (43\%) metastasized in the mutant cohort (Suppl. Fig. 12). Lymphoma incidence did not considerably differ between wt and mutant with $17 \%$ of wt and $10 \%$ in 

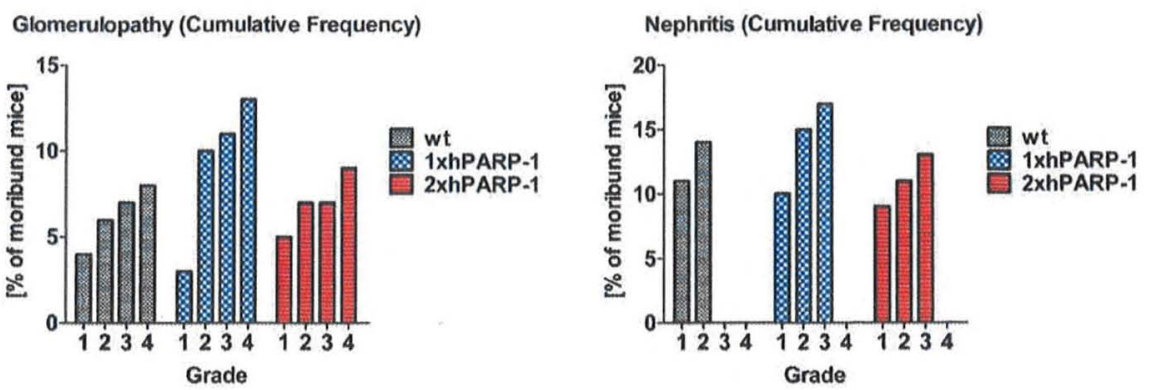

Hepatitis (Cumulative Frequency)

Myocarditis/Cardiac Fibrosis (Cumulative Frequency)
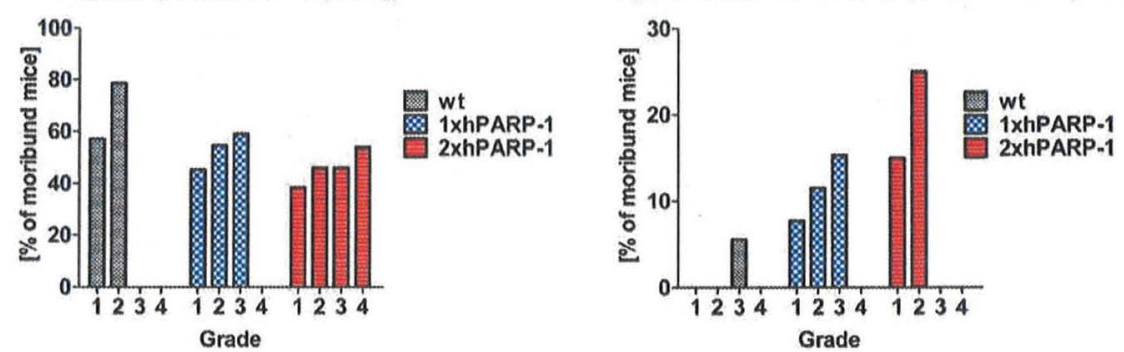

Pneumonitis (Cumulative Frequency)

wt

PARP-1 2XhPARP-1

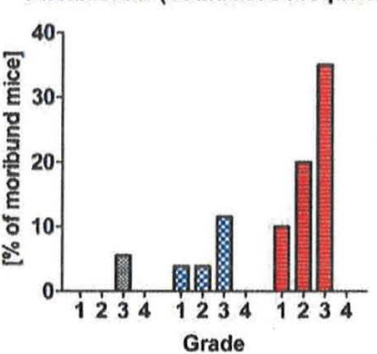

Dermatitis (Cumulative Frequency)

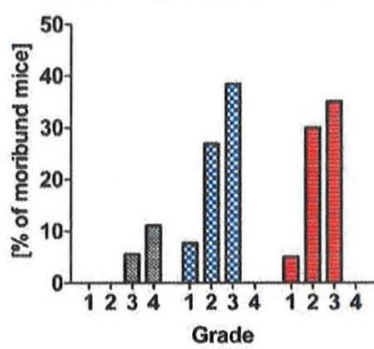

Fig. 8. Cumulative disease frequencies of non-neoplastic lesions of deceased or moribund wild-type and hPARP-1 mice. Non-neoplastic lesions of wild-type (wt), mutant hemizygous ( $\left.1 \times h P A R^{-}-1\right)$, and mutant homozygous $(2 \times h P A R P-1)$ mice were graded as described in Section 2 ranging from mild (grade 1$)$ to severe (grade 4$)$ pathological alterations. Cumulative frequencies of disease grades are shown.

homozygous mutant mice affected. First time of appearance of lymphomas was 17.9 months of age in wt and 8.7 months of age in mutant mice.

In conclusion, overall tumor load was not considerably different in mutant compared to wt mice, however the spectrum of the neoplasms that occurred was shifted, as mutant animals developed fewer sarcomas, but more adenomas and carcinomas, in particular hepatocellular carcinomas, compared to wt.

\subsection{Characterization of potential mechanisms of disease in hPARP-1 mice}

During histopathological analyses of aging mouse cohorts, we incidentally discovered cases of anemia in mutant moribund mice. Therefore, we studied hematological parameters of apparently healthy mutant mice compared to their wt littermate controls at the age of one and two years. Analyses revealed normocytic normochromic anemia in the mutant mice. While erythrocyte volume and intracellular hemoglobin concentration remained normal, hematocrit levels decreased by $19.1 \%(P=0.06)$, erythrocyte counts by $18.6 \%(P=0.06)$ and overall blood-hemoglobin content by $19.4 \%(P<0.05)$ at the age of one year (data not shown). This effect reached higher statistical significance at the age of two years with a decrease in hematocrit by $17.8 \%$, in erythrocyte counts by $16.2 \%$, and in overall hemoglobin content by $17.4 \%$ (Fig. 10). Moreover, at this age the fraction of monocytes of the total white blood cell count significantly increased from $2.18 \%$ in wt mice to
$2.71 \%$ in homozygous mutant mice (Fig. 10). This form of anemia is indicative of anemia of chronic disease which is considered a consequence of progressive chronic inflammation (Zarychanski and Houston, 2008). Since PARP-1 acts as an essential coactivator of the pro-inflammatory transcription factor NF- $\kappa \mathrm{B}$, we studied expression levels of selected NF- $\kappa \mathrm{B}$ responsive genes, i.e., Tnf- $\alpha$, II1 , and $11-6$. Consistent with the multiple signs of inflammation in hPARP-1 mice, such as splenomegaly, anemia, and the premature development of several inflammation-related pathologies, TNF- $\alpha$ and IL-1 mRNA levels were upregulated by more than $100 \%$ in homozygous mutant mice. On the other hand, and rather unexpectedly, levels of IL-6 dropped by $89 \%$ in the group of mutant mice (Fig. 11A).

Since PARP-1 exhibits a profound role during multiple pathways of DNA repair, such as base excision repair and nonhomologous end joining, we studied the effect of ectopic hPARP-1 expression on DNA repair kinetics upon genotoxic stress (X-ray irradiation) using the technique of automated fluorimetric detection of alkaline DNA unwinding (FADU) (Moreno-Villanueva et al., 2009). Of note, we detected a significant delay in DNA repair kinetics in freshly isolated splenocytes from young adolescent homozygous mutant mice compared to wt controls (Fig. 11B).

In summary, hPARP-1 mice progressively developed normocytic, normochromic anemia, which is indicative of anemia of chronic disease, and showed dysregulation of $\mathrm{NF}-\mathrm{KB}$ responsive genes. Moreover, cells from homozygous mutant mice exhibited delayed DNA repair kinetics. 


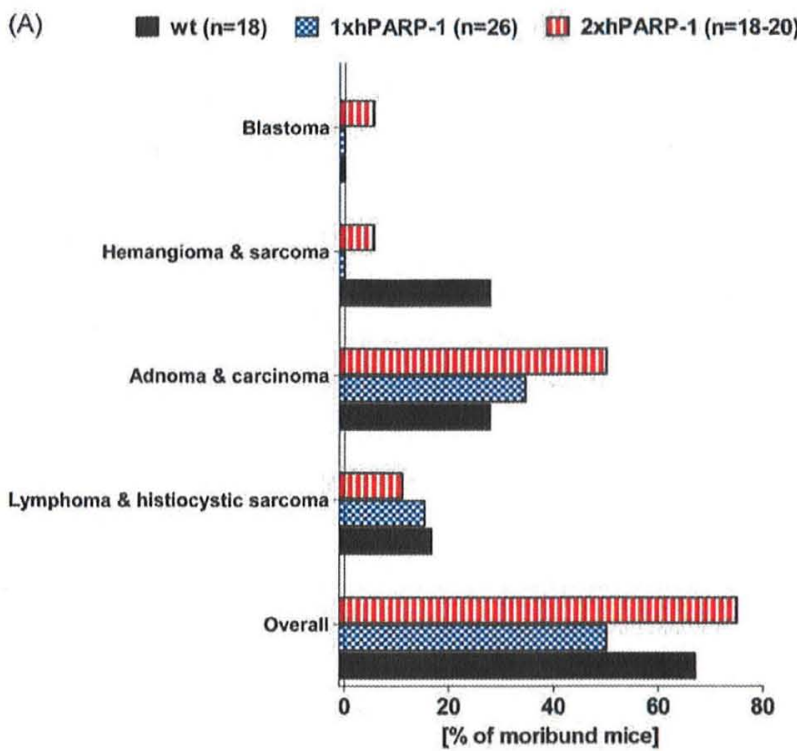

(B) HCC (Cumulative Frequency)

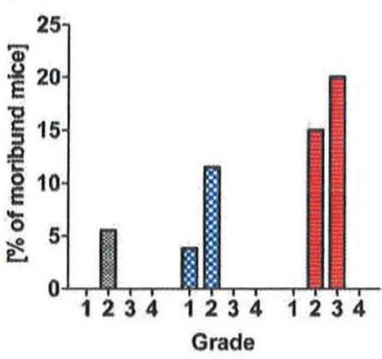

Lymphoma Distribution



Hemangioma/sarcoma (Cumulative Frequency) wt

1XhPARP-1

2XhPARP-1

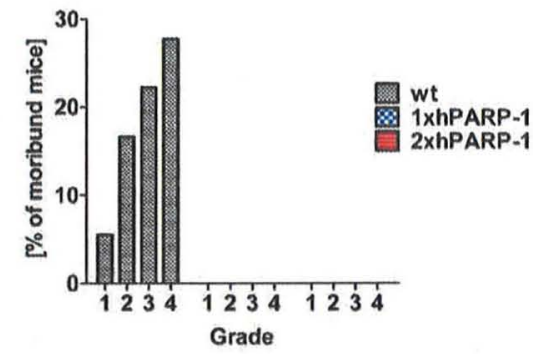

Pulmonary Adenoma/CA (Cumulative Frequency)

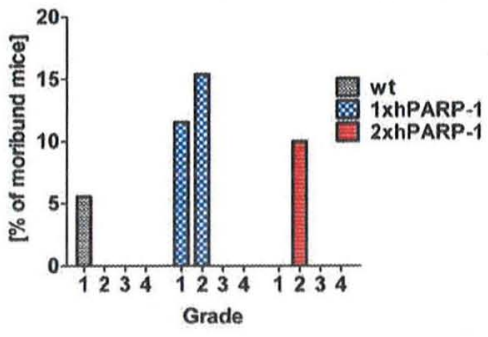

Fig. 9. Neoplastic lesions in deceased or moribund wild-type and hPARP-1 mice. (A) Frequencies of neoplastic lesions in wild-type (wt) and hPARP-1 mice as classified by tumor origin. Two tumors from homozygous mutant mice could not be classified with absolute certainty; therefore, these mice were omitted from respective tumor analysis. (B) Cumulative frequencies of tumor grades. Neoplastic lesions were graded as described in Section 2 ranging from small local tumors (grade 1 ) to tumor metastas es in four or more organs (grade 4). Only high-grade lymphomas were detected in our mouse cohorts and therefore lymphomas were graded as grade 3 lesions in every case.

\section{Discussion}

Recently, we generated a novel mutant mouse model with ectopic expression of hPARP-1, i.e., hPARP-1 mice (Mangerich et al., 2009). Chromosome 1 of these mice carries one ectopic copy of heterologous hPARP-1 in addition to the endogenous mParp-1 (Mangerich et al., 2009). In the current study, we report the detailed phenotypic characterization of these mice.

Screening of PARP-1 expression in different wt mouse tissues revealed high endogenous PARP-1 levels in the lymphoid and reproductive organs and moderate to low PARP-1 expression in all other organs tested (Fig. 1). These data confirm previous studies analyzing PARP-1 expression at mRNA level in different mouse tissues indicating that PARP-1 protein levels are mainly main- tained through transcriptional regulation (Hakme et al., 2008; Menegazzi et al., 1991; Ogura et al., 1990). The fact that no PARP-1 expression was detectable in the intestine in our study might be related to the finding by Hakme and colleagues showing that presence of PARP-1 mRNA is restricted to the crypts of the intestine (Hakme et al., 2008). Therefore overall PARP-1 levels in the intestine may be below the detection limit. The finding that heterologous hPARP-1 protein levels correlate with those of the endogenous MPARP-1 throughout the different mouse tissues is in agreement with the fact that the transgenic hPARP-1 coding sequence is transcriptionally controlled by the mParp-1 promoter (Fig. 1). Individual analyses of hPARP-1 and mPARP-1 protein levels revealed that hPARP-1 is expressed in a gene-dose-dependent manner in mutant mice and mPARP-1 levels declined correspond- 

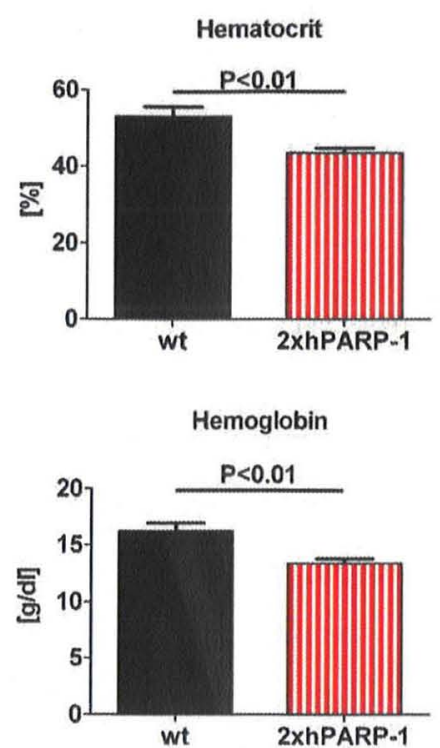

White Blood Cell Count

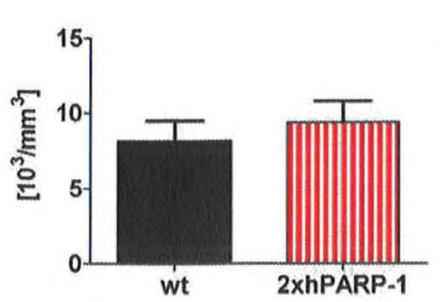

Mean Cell Hemoglobin Concentration

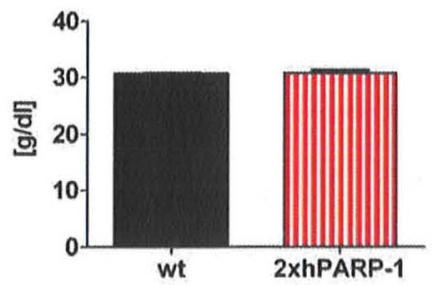

Monocytes in \% of WBC

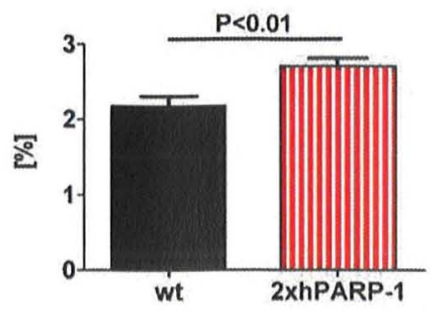

Mean Red Blood Cell Volume (MCV)

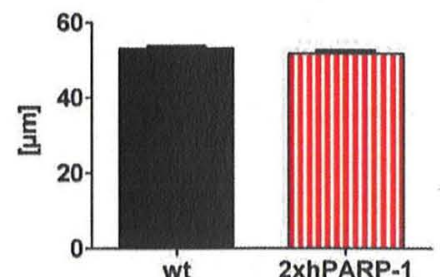

Fig. 10. Hematological analysis of two-year old wild-type (wt) and homozygous mutant $(2 \times h P A R P-1)$ mice. The differences detected in hematological parameters are characteristic of normocytic, normochromic anemia, which is indicative of anemia of chronic disease. Statistical analysis was performed using Student's $t$-test. $n=8$, mean \pm SEM. WBC, white blood cell count.
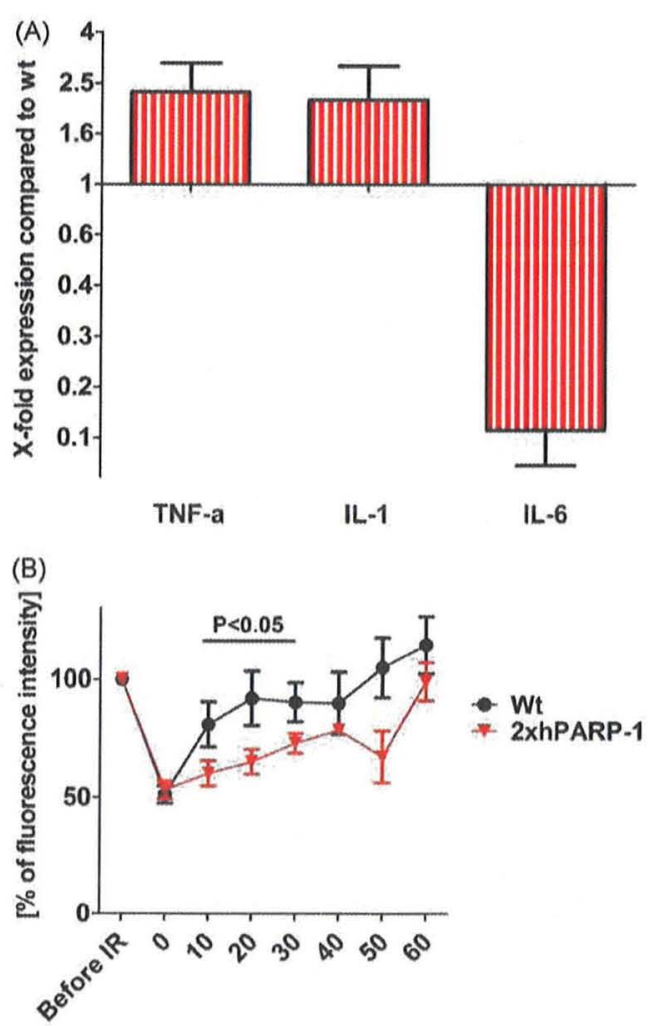

[Min after irradiation with $3.8 \mathrm{~Gy}$ ]

Fig. 11. Analyses of gene transcription and DNA repair. (A) Cytokine expression in one-year old $h P A R P-1$ mice. mRNA levels of TNF- $\alpha$, IL-1 $\alpha$, and IL- 6 of homozygous mutant $(2 \times h P A R P-1)$ mice were compared to wild-type $(\mathrm{wt})$ littermates by quantitative real-time PCR. Data are from five individual experiments, each performed in technical triplicates, means \pm SEM. (B) DNA repair kinetics of splenocytes isolated from age-matched 1- to 3-month old wt and homozygous mutant (2xhPARP-1) mice. Splenocytes were irradiated with X-rays ( 3.8 Gy and repair kinetics evaluated as described in Section 2 using the automated FADU assay. Statistical analysis was performed using two-way ANOVA. Data are from six individual experiments, each performed in technical triplicates. Shown are means \pm SEM. ingly (Fig. 2). These results underline previous reports demonstrating that PARP-1 binds to specific DNA structures and motifs within its own promoter region to inhibit its own transcription in an autoregulatory manner (Lonskaya et al., 2005; Oei et al., 1994; Soldatenkov et al., 2002; Vidakovic et al., 2009). Thereby, hPARP-1 accounts for about $50 \%$ of total PARP-1 in the homozygous hPARP-1 animals.

For the phenotypic interpretation of mutant mice, it should be noted that gene loci other than Parp-1, ie., Lin-9 and Gm821, are affected in those mice, which might contribute at least in part to the phenotype of mutant mice (Mangerich et al., 2009). However, a smaller aging cohort of a second mouse line (Parp1 ${ }^{\text {tm1.1(PARP 1)Abu }}$ hPARP-1-\#113), which was obtained from another ES cell clone, carries no duplication of Lin-9 (Mangerich et al., 2009), but showed also impaired survival rates and development of corresponding pathologies (Suppl. Fig. 5). This finding indicates that targeting of Lin-9 is very unlikely to be the main contributor to the observed phenotype in mice analyzed in this study (Parp1 $1^{\text {tm1.1(PARP1)Abu, }}$ hPARP-1-\#225). With respect to Gm821, in general, so far it is not known if Gm821 (gene model 821) gives rise to a functional protein at all. Thus, taken together, it is to be expected that the phenotype observed in hPARP-1 mice is indeed caused by ectopic expression of hPARP-1.

Except for some incidences of death within the group of mutant mice before the age of three months, no severe phenotypic alterations were observed until adolescence of these animals. However, metabolic alterations, such as increased body weight and impaired glucose tolerance became apparent in the mutant cohort during that period (Figs. 3 and 4 and Suppl. Fig. 2). While at the age of 5 months glucose metabolism was unchanged in females, mutant males developed glucose intolerance compared to wt controls at this age, thus providing evidence for a prediabetic state of these animals. In future studies, it remains to be seen if the detected glucose intolerance of mutant males is also accompanied by changes in insulin levels and insulin sensitivity. Since under the conditions tested there were no indications for dysregulation of blood lipids (Suppl. Fig. 3) nor for the development of an acute diabetic condition (Fig. 4), it might be interesting to place hPARP-1 mice on a high fat diet in order to further challenge the metabolic regulatory systems in these mice. Interestingly, although Parp $-1^{-1-}$ mice were reported 
to be leaner compared to their wt littermates (de Murcia et al., 1997) a recent study demonstrated that PARP-1 $1^{-1}$ mice, if fed with a high fat diet, are susceptible to diet-induced obesity, insulin resistance, and glucose intolerance (Devalaraja-Narashimha and Padanilam, 2010 ). With regards to gender differences in glucose metabolism of wt mice, it was shown previously that $\mathrm{C} 57 \mathrm{BL} / 6$ are susceptible to develop glucose intolerance and that male C57BL/6 mice exhibit higher levels of glycation of hemoglobin (Dubuc et al., 1993; Kaku et al., 1988). However, further evaluation is indicated regarding our finding of differences in glucose metabolic responses between wt males and females (Fig. 4). Possible causes for the detected gender differences in glucose tolerance may be due to our experimental setting ( $6 \mathrm{~h}$ of daytime fasting, application of $2 \mathrm{mg}$ glucose per gram body weight) and/or different stress responses of sexes during the test procedure.

The survival of our wt population was in the range of or even better than the published data on the B6;129 strain (Fig. 5) (Haines et al., 2001; Hursting et al., 1997). Importantly, the absence of pathogens in our mouse colony was confirmed on a regular basis. In accordance with previous reports on aging $\mathrm{B} 6 ; 129$ mice (Haines et al., 2001; Hoenerhoff et al., 2006; Maronpot et al., 1999; Ward et al., 2000), non-neoplastic lesions in old wt mice comprised nephropathies, low-grade hepatitis, cardiomyopathies, crystal pneumonitis, and inflammatory skin lesions (Fig. 8 and Suppl. Fig. 6). These pathologies were observed in the group of mutant mice at higher frequencies, higher pathological grades and at earlier onsets compared to wt littermates, suggesting that aging hPARP-1 mice are prone to develop pathologies related to inflammatory processes at an earlier age (Fig. 7 and Suppl. Fig. 6). In particular grade 3 and $\mathbf{4}$ histopathological alterations like nephropathies, hepatitis, pneumonitis, and dermatitis, which are considered as potential causes of death, occurred within the first year of life exclusively in the mutant cohort, thereby contributing to the increased mortality in this group (Suppl. Fig. 6). Strikingly, Parp- $1^{-1-}$ mice are protected from several inflammation-related diseases (Beneke, 2008). With regards to nephropathies, it is noteworthy that PARP-1 itself as well as its direct interaction partner NF-KB were implicated in the etiology of such diseases (Auwardt et al, 2000; Jog et al., 2009). The finding of islet cell hyperplasia in $h P A R P-1$ mice should be interpreted with caution, because exact morphometric measurements have not been conducted. Nevertheless, it is noteworthy that hyperplasia of the islets of Langerhans can be caused by increased tissue inflammation (Bouwens and Rooman, 2005; Campbell et al., 1994). With regards to the detected high-grade hepatitis in the cohort of mutant mice, the exact etiology of these lesions remains unknown. Since our mouse colony repeatedly tested negative for Mouse Hepatitis Virus, it might be possible that the affected mice developed autoimmune hepatitis. In general, autoimmune hepatitis is a necroinflammatory, progressive, chronic disease of unknown cause (Krawitt, 2006). Interestingly, PARP-1 itself was implicated in the development of autoimmune disease (GraderBeck et al., 2007; Jeoung et al., 2004; Jog et al., 2009). Although we did not detect autoantibodies in hPARP-1 mice (data not shown), we cannot exclude that in the mice with hepatitis an autoimmunedriven reaction occurred.

In summary, the observed pathologies in hPARP-1 mice clearly show that these animals are prone to develop inflammationrelated diseases. A pro-inflammatory status of hPARP-1 mice is further supported by the development of non-neoplastic splenomegaly and normocytic, normochromic anemia in hPARP- 1 mice. This type of anemia is indicative of anemia of chronic disease and is considered a result of increased inflammatory status (Hedrich, 2004; Zarychanski and Houston, 2008). Such an interpretation of the observed phenotype is supported by the fact that PARP-1 participates in the development of many inflammatory diseases due to its overactivation under pathophysiological conditions and or due to its function as a coactivator of NF- $\mathrm{KB}$ (Beneke, 2008; Hassa and Hottiger, 2002; Jagtap and Szabo, 2005).

Cancer and aging are closely connected, and cancer represents one of the major age-related diseases in the mouse and in man (Maslov and Vijg, 2009). Although hPARP-1 homozygotes developed tumors at slightly higher frequencies compared to wt, in general, hPARP-1 mice were not especially tumor-prone compared to their wt littermates. However, when evaluating the tumor spectrum in greater detail, we identified substantial changes in the type of tumors appearing in hPARP-1 mice compared to wt controls. In general, lymphomas were described as one of the most common form of spontaneous malignancies in aging $B 6 ; 129$ mice, which is in accordance with findings in our wt cohort (Haines et al., 2001; Ward et al., 2000). Moreover, about one third of our wt mice developed hemangiomas and hemangiosarcomas (Fig. 9 and Suppl Fig. 11). Although hemangiomas and hemangiosarcomas were described to develop in aging cohorts of this type of strain, such high incidence of vascular neoplasms was not observed before and might reflect potential variations of the $129 \mathrm{P} 2 /$ olaHsd substrain (Haines et al., 2001; Ward et al., 2000). In contrast to wt mice, mutant animals developed fewer mesenchyme-derived tumors, in particular hemangiosarcomas (Fig. 9 and Suppl. Fig. 11). In contrast, incidences of epithelial-derived tumors increased from $28 \%$ in the wt cohort to $50 \%$ in the homozygous mutant cohort. In particular, four out of 20 homozygous mutant mice (20\%) developed hepatocellular carcinomas with first appearance at the age of 19 months compared to only one out of $16 \mathrm{wt}$ mice (6\%) which developed hepatocellular adenomas containing focal carcinomas at the age of 25 months. A previous study showed that in an aging $B 6 ; 129$ cohort about $10 \%$ of mice developed hepatocellular adenomas and only $1 \%$ hepatocellular carcinomas (Haines et al,, 2001). In general, spontaneous hepatocellular carcinomas in the mouse are slow growing and rarely metastasize (Turusov, 1979). In contrast, in hPARP-1 homozygotes $50 \%$ of the hepatocellular carcinomas metastasized to other tissues (Fig. 9 and Suppl. Figs. 11 and 12). Given the moderate expression of mPARP-1 and hPARP- 1 in the liver of mutant animals, it is tempting to speculate that only a subset of cells in the liver, e.g., cells of the immune system such as Kupfer cells, show high expression of murine and human PARP-1.

Chronic diseases and inflammation are tightly linked, and chronic inflammation increases the risk of developing many types of diseases including cancer (Mantovani et al., 2008). In general, chronic inflammation gives rise to reactive oxygen and nitrogen species which cause damage to all cellular macromolecules including DNA (Son et al., 2008). On the one hand, this can lead to further tissue damage, thereby promoting chronic inflammation and over time leading to progressive tissue deterioration and development of chronic diseases. On the other hand, constant DNA damage can lead to mutations and genomic instability, thus, driving carcinogenesis. The findings that DNA repair was delayed in $h P A R P-1$ homozygotes (Fig. 11) taken together with multiple signs of inflammation in $h P A R P-1$ mice provide a mechanistic interpretation for the observed phenotype of hPARP-1 mice. Regarding the development of aggressive forms of hepatocellular carcinoma for instance, it thus can be hypothesized that an enhanced inflammatory status in the liver, which may contribute to increased oxidative stress and DNA damage, leads to tumor initiation and promotion even enhanced by impaired DNA repair.

Although our previous in vitro results demonstrated that purified hPARP-1 exhibits higher poly(ADP-ribosyl)ation capacity compared to its rodent orthologue and despite the fact that basal $\mathrm{NAD}^{+}$levels were significantly decreased in hPARP-1-expressing mouse ES cells, we have no indications so far for an altered poly(ADP-ribosyl)ation capacity of $h$ PARP- 1 cells in vivo (Suppl. Fig. 
1). Therefore, we hypothesize that regulatory mechanisms in vivo seem to be able to keep $\mathrm{NAD}^{+}$levels and poly(ADP-ribosyl)ation in balance. However, at present we cannot exclude that mutant cells encounter alterations in poly(ADP-ribose) metabolism under specific conditions, thereby contributing at least in part to phenotypic alterations.

PARP-1 interacts with and modifies dozens if not hundreds of proteins. Kinetics of protein interactions are of great importance for the function of PARP-1. Thus, it is tempting to speculate that sequence differences between mouse und human PARP-1 (overall homology $\sim 95 \%$ ) affect interactions of hPARP-1 with murine proteins. As a result, this may lead to changes in cellular functions, either gain of function or loss of function, depending on the strength and the kinetics of the interaction. Thus, it is possible that delayed DNA repair in $h P A R P-1$ cells is caused either by impaired or by stronger, ie., dominant-negative, interactions of hPARP-1 with mouse DNA repair factors, such as XRCC1 and DNA-PK. Furthermore, it is conceivable that PARP-1-NF- $K B$ interaction is altered in $h P A R P-1$ cells leading to increased NF- $\kappa B$ activity and over time to the development of a broad spectrum of inflammatory diseases. This notion is supported by the finding that expression of some NF$\kappa \mathrm{B}$-mediated cytokines such as TNF- $\alpha$ and $\mathrm{Il}-1$ is upregulated in hPARP-1 animals (Fig. 11). Even though the finding of downregulation of IL-6 seems paradoxical at first glance, the role of IL-6 in chronic inflammation is reported to be multifaceted and to depend on the status of the inflammatory reaction (Gabay, 2006). Thus, downregulation of IL-6 expression might represent a compensatory feed-back mechanism of the organism in an attempt to compensate for the higher inflammatory burden in mutant mice.

A direct relationship exists between physiological aging and increasing incidence of age-related and chronic inflammatory diseases (Hayden, 2007; Masoro, 2006). During aging, the continuous pressure on the immune system caused by repeated antigen stimulation could lead to an increase in activated immune cells and secretion of pro-inflammatory cytokines, a phenomenon known as 'inflammaging' (De Martinis et al., 2005; Finch, 2007; Franceschi et al., 2000). Due to the fact that maximum lifespan is not altered in hPARP-1 mice compared to wt mice, the hPARP-1 cohort in total did not display a general premature aging phenotype. Yet, in addition to the finding that mutant mice developed age-associated diseases prematurely, some findings of our study, such as development of kyphosis and impaired hair growth of $h P A R P-1$ mice, are in support of the view that some of the affected mice displayed segmental premature aging. Kyphosis is generally considered as potential sign of premature aging in mice (de Boer et al., 2002; Razzaque et al., 2006) and assessment of hair growth was formerly described as a potential biomarker of aging in the mouse, reflecting stem cell aging (Harrison and Archer, 1988; Tyner et al., 2002).

In conclusion, here we present a novel mouse model with ectopic expression of human PARP-1 to study the role of PARP-1 on an organismal level. Human PARP-1 mice exhibited a multifactorial pathological phenotype showing impaired survival, a shift in the tumor spectrum of spontaneous tumors, as well as metabolic changes such as increased body weights and gender-specific impaired glucose tolerance. Furthermore, mutant mice developed inflammation and age-related pathologies prematurely. We propose that in some aspects, $h P A R P-1$ mice could serve as a manmalian model of so-called "inflammaging".

\section{Acknowledgements}

We gratefully acknowledge the advice of Prof. Rüdiger Wanke (LMU Munich, Munich, Germany) regarding histopathological analyses of mice. We thank Barbara Bausch, Gudrun von Scheven, Heidi Henseleit, and Birgitt Planitz for competent technical assistance. We thank Drs. Gerald Mende and Dieter Schopper for help regarding glucose tolerance testing and expert veterinary advice. We thank Dr. Sascha Beneke for valuable discussion and Dr. Tobias Eltze for technical introduction into the FADU technique. AM and OTB were supported by the 'Studienstiftung des Deutschen Volkes', and $\mathrm{AM}$ and $\mathrm{BH}$ were supported by the 'Deutsche Forschungsgemeinschaft' (DFG) (International Research Training Group 1331).

\section{Appendix A. Supplementary data}

Supplementary data associated with this article can be found, in the online version, at doi: $10.1016 / \mathrm{j} . \mathrm{mad} .2010 .05 .005$.

\section{References}

Aguilar-Quesada, R, Munoz-Gamez, J.A., Martin-Oliva, D., Peralta-Leal, A., QuilesPerez, R, Rodriguez-Vargas, J.M., de Almodovar, M.R, Conde, C., Ruiz-Extremera, A., Oliver, F.., 2007. Modulation of transcription by PARP-1: consequences in carcinogenesis and inflammation. Curr. Med. Chem. 14, 1179-1187.

Aguilar Quesada, $R$, Munoz-Gamez, J.A., Martin-oliva, D., Peralta, $A$, Valenzuela, $T$., Martinez-Romero, R, Quiles-Perez, R., Menissier de Murcia, J. De Murcia, $G$., Ruiz de Almodovar, M., Oliver, F.J., 2007. Interaction between ATM and PARP-1 in response to DNA damage and sensitization of ATM deficient cells through PARP inhibition. BMC Mol. Biol. 8, 29.

Altmeyer, M. Messner, S., Hassa, P.O., Fey, M., Hottiger, M.O., 2009. Molecular mechanism of poly(ADP-ribosyl)ation by PARPl and identification of Iysine residues as ADP-ribose acceptor sites. Nucleic Acids Res. 37, 3723-3738.

Andrikopoulos, S., Blair, A.R, Deluca, N., Fam, B.C., Proietto, I., 2008. Evaluating the glucose tolerance test in mice. Am. J. Physiol. Endocrinol. Metab. 295, E1323E1332.

Auwardt, R.B., Mudge, S.J., Power, D.A., 2000. Transcription factor NF-kappaB in glomerulonephritis. Nephrology 5, 71-82.

Beneke, S., 2008. Poly (ADP-ribose) polymer ase activity in different pathologies-the link to inflammation and infarction. Exp. Gerontol, 43, 605-614.

Beneke, S., Alvarez-Gonzalez, R. Bürkle, A., 2000. Comparative characterisation of poly(ADP-ribose) polymerase-1 from two mammalian species with different life span. Exp. Gerontol. 35, 989-1002.

Beneke, $S$., Bürkle, $A$. 2007. Poly(ADP-ribosyl)ation in mammalian ageing. Nucleic Acids Res. 35, 7456 -7465.

Beneke, S., Cohausz, O., Malanga, M., Boukamp, P., Althaus, F, Bürkle, A, 2008. Rapid regulation of telomere length is mediated by poly(ADP ribose) polymerase-1. Nucleic Acids Res. $36,6309 \ldots 6317$.

Beneke, S., Scherr, A.L., Ponath, V., Popp, O., Bürkle, A., 2010. Enzyme characteristics of recombinant poly( $A D P$-ribose) polymerases- 1 of rat and human origin mirror the correlation between cellular poly(ADP-ribosyl)ation capacity and species. specific life span. Mech. Ageing Dev. 131, 366-369.

Bemofsky, C. Swan, M., 1973. An improved cycling assay for nicotinamide adenine dinucleotide Anal. Biochem. 53, 452-458.

Botwens, L, Rooman, 1, 2005. Regulation of pancreatic beta-cell mass. Physiol. Rev. 85, $1255-1270$.

Braunwald, E., Fauci, A.S., Kasper, D.L, Hauser, S.L, Longo, D.L, Jameson, I.L. 2001. Harrison's Principles of Internal Medicine, 15 th Ed. McGraw-Hill.

Burkart, V., Wang, Z.Q., Radons, J, Heller, B., Herceg, Z., Stingl, L., Wagner, E.F., Kolb, H. 1999. Mice lacking the poly(ADP-ribose) polymerase gene are resistant to pancreatic beta-cell destruction and diabetes development induced by streptozocin. Nat. Med. 5, 314-319.

Bürkle, $A_{n}$ 2005. Poly (ADP-ribose): the most elaborate metabolite of $\mathrm{NAD}^{+}$. FEBS ]. $272,4576-4589$.

Campbell, I.L., Hobbs, M.V., Dockter, l., Oldstone, M.B., Allison, J., 1994. Islet inflammation and hyperplasia induced by the pancreatic islet-specific overexpression of interleukin- 6 in transgenic mice. Am. J. Pathol. 145, 157-166.

Chevanne, M., Calia, C., Zampieri, M., Cecchinelli, B., Caldini, R., Monti, D., B ucci, L., Franceschi, C., Caiafa, P., 2007. Oxidative DNA damage repair and parp 1 and parp 2 expression in epstein-barr virus-immortalized $B$ lymphocyte cells and parp 2 expression in epstein-barr virus-immortalized B lymphocyte cells $191-204$.

Cohen-Armon, M., Visochek, $L_{2}$ Rozensal, D., Kalal, A., Geistrikh, l, Klein, R., BendetzNezer, S., Yao, Z., Seger R, 2007. DNA-independent PARP-1 activation by phosphorylated ERK2 increases Elk1 activity: a link to histone acetylation. Mol. Cell 25, 297-308.

d'Adda di Fagagna, F., Hande, M.P., Tong, W.M., Lansdorp, P.M., Wang, Z.Q. Jackson, S.P. 1999. Functions of poly(ADP-ribose) polymerase in controlling telomere length and chromosomal stability. Nat. Genet. 23, 76-80.

de Boer, J., Andressoo, J.O., de Wit, J., Huijmans, J., Beems, R.B., van Steeg, H., Weeda, G., van der Horst, G.T, van Leeuwen, W., Themmen, A.P., Meradii, M., Hoeijmakers, J.H. 2002. Premature aging in mice deficient in DNA repair and transcription. Science 296, 1276-1279.

De Martinis, M., Franceschi, C., Monti, D., Ginaldi, L, 2005. Inflamm-ageing and lifelong antigenic load as major determinants of ageing rate and longeviry. FEBS Lett. $579,2035-2039$. 
de Murcia, J.M., Niedergang, C., Trucco, C., Ricoul, M., Dutrillaux, B., Mark, M., Oliver F.J., Masson, M., Dierich, $A$, LeMeur, M., Walztinger, C, Chambon, P. de Murcia, $G$., 1997. Requirement of poly(ADP-ribose) polymerase in recovery from DNA damage in mice and in cells. PNAS 94,7303-7307

Devalaraja-Narashimha, K., Padanilam, B., 2010. Parp-1 deficiency exacerbates dietinduced obesity in mice. . Endocrinol. 205, 24.3-252.

Dubuc, P.U. Scott, B.K. Peterson, C.M. 1993. Sex differences in glycated hemoglobin in diabetic and non-diabetic C57BU6 mice. Diabetes Res. Clin. Pract 21,95-101.

El Ramy, R., Magroun, N., Messadecq, N., Gauthier, LR, Boussin, F.D., KolthurSeetharam, U., Schreiber, V., McBturney, M.W., Sassone-Corsi, P., Dantzer, F. 2009. Functional interplay between Parp- 1 and $S i r T 1$ in genome integrity and chromatin-based processes. Cell. Mol. Life Sci. 66, 3219-3234

Fahrer, J., Kranaster, R, Altmeyer, M., Marx, A., Bürkle, A., 2007. Quantitative analysis of the binding affinity of poly(ADP-ribose) to specific binding proteins as a function of chain length. Nucleic Acids Res. 35 , e143.

Finch, C.F. 2007. The Biology of Human Longevity. Elsevier Acadenic Press.

Franceschi, C., Bonafe, M., Valensin, S., Olivieri, F., De Luca, M. Ottaviani, E., De Benedictis, $G_{n}$ 2000. Inflamm-aging. An evolutionary perspective on immuno senescence. Ann. N.Y. Acad. Sci. 908, 244-254.

Gabay, $C_{0}, 2006$. Interleukin 6 and chronic inflammation. Arthritis Res. Ther. 8 (Suppl 2), $\$ 3$.

Gagne, J.P., Isabelle, M., Lo, KS., Bourassa, S., Hendzel, M.J., Dawson, V.L., Dawson T.M., Poirier, G.G., 2008. Proteome-wide identification of poly(ADP-ribose) binding proteins and poly(ADP-ribose)-associated protein complexes. Nucleic Acids Res. 36, 6959-6976.

Grader-Beck, T., Casciola-Rosen, L, Lang, T.J., Puliaev, R., Rosen, A., Via, CS., 2007 Apoptotic splenocytes drive the autoimmune response to poly(ADP-ribose) polymerase 1 in a murine model of lupus. I. Immunol. 178, 95-102.

Grube, K., Bürkle, A., 1992. Poly(ADP-ribose) polymerase activity in mononuclear leukocytes of 13 mammalian species correlates with species-specific life span Proc. Natl. Acad. Sci. U.S.A. 89, 11759-11763.

Haince, J.F, Kozlov, S., Dawson, V.L, Dawson, T.M., Hendzel, M.J., Lavin, M.F, Poirier G.G., 2007. Ataxia telangiectasia mutated (ATM) signaling network is modulated by a novel PAR-dependent pathway in the early response to DNA damaging agents. J. Biol. Chem. 282, 16441-16453.

Haines, D.C. Chattopadhyay, S., Ward, J.M., 2001. Pathology of aging B6;129 mice. Toxicol. Pathol. 29, 653-661

Hakme, A., Huber, A., Dolle, P., Schreiber, V., 2008. The macroPARP genes Parp -9 and Patp-14 are developmentally and differentially regulated in mouse tissues. Dev. Dyn. 237, 209-215

Harrison, D.E., Archer, J.R., 1988. Biomarkers of aging: tissue markers. Future research needs, strategies, directions and priorities. Exp. Gerontol. 23, 309-325.

Hassa, P.O., Covic, M., Hasan, S., Imhof, R., Hottiger, M.O., 2001. The enzymatic and DNA binding activity of PARP-1 are not required for NF kappa $B$ coactivator function. J. Biol. Chem. 276, 45588-45597.

Hassa, P.O, Haenni, S.S., Buerki, C., Meier, N.I., Lane, W.S., Owen, H., Gersbach, M. Imhof, R., Hottiger, M.O., 2005. Acetylation of poly(ADP-ribose) polymerase-1 by $\mathrm{p} 300 / \mathrm{CREB}$-binding protein regulates coactivation of NF-KB-dependent transcription, J. Biol. Chem. 280, 40450-40464.

Hassa, P.O., Hottiger, M.O., 2002. The functional role of poly(ADP-ribose)polymerase 1 as novel coactivator of NF-kappaB in inflammatory disorders. Cell. Mol. Life Sci. 59, 1534-1553.

Hayden, E.C., 2007. Age research: a new angle on 'old'. Nature 450, 603-605.

Hedrich, H.J., 2004. The laboratory mouse. Elsevier Academic Press, London.

Heeres, J.T., Hergenrother, P.]., 2007. Poly(ADP-ribose) makes a date with death Curr. Opin. Chem. Biol. 11,644-653.

Herbach, N., Goeke, B., Schneider, M., Hermanns, W., Wolf, E., Wanke, R., 2005. Overexpression of a dominant negative GIP receptor in transgenic mice results in disturbed postnatal pancreatic islet and beta-cell developnent. Regul. Pept $125,103-117$.

Hoenerhoff, M.I., Starost, M.F., Ward, J.M. 2006. Eosinophilic crystalline pneumonia as a major cause of death in $12954 / 5 v J a e$ mice. Vet. Pathol. $43,682-688$

Hottiger, M.O., Hassa, P.O., Luscher, B., Schuler, H., Koch-Nolte, F., 2010. Toward a unified nomenclature for mammalian ADP-ribosyltransferases. Trends Bio chem. Sci. $35,208-219$.

Hursting, S.D., Perkins, S.N., Brown, CC, Haines, D.C., Phang, J.M., 1997. Calorie restriction induces a p53-independent delay of spontaneous carcinogenesis in p53-deficient and wild-type mice. Cancer Res. 57, 2843-2846.

Ikeno, Y., Bronson, R. T., Hubbard, G.B., Lee, S., Bartke, A., 2003. Delayed occurrence of fatal neoplastic diseases in ames dwarf mice: correlation to extended longevity. 1. Gerontol. A Biol. Sci. Med. Sci. 58, 291-296.

Jacobson, E. L, Jacobson, M.K., 1976. Pyridine nucleotide levels as a function of growth in nomal and transformed $3 \Gamma 3$ cells. Arch. Biochem. Biophys. 175, 627 634.

Jagtap, r, $_{\text {, }}$ Sabo, $C_{\text {, }}$ 2005. Poly (ADP ribose) polymer ase and the therapeutic effects of its inhibitors. Nat. Rev. Drug Discov. $4,421-440$

Jeoung, D., Lim, Y, Lee, E.B., Lee, S., Kim, H.Y., Lee, H., Song, Y.W., 2004, Identification of autoantibody against poly (ADP-ribose) polymer ase (PARP) fragment as a serological marker in systemic lupus ery thematosus. J. Autoimmun. 22 $87-94$.

Zhang. Jie, 2003. Are poly(ADP-ribosyl)ation by PARP-1 and deacetylation by Sir2 linked? BioEssays 25, 808-814

Jog, N.R, Dinnall, J.A., Gallucci, S., Madaio, M.P., Caricchio, R, 2009. Poly(ADP-ribose) polymerase-1 regulates the progression of autoimmune nephritis in males by inducing necrotic cell death and modulating inflammation. J. Immunol. 182, $7297-7306$
Kahn, S.E., Hull RL., Utzschneider, KM., 2006. Mechanisms linking obesity to insulin resistance and type 2 diabetes. Nature $444,840-846$.

Kaku, K., Fiedorek Jr. F.T., Province, M., Permutt, M.A., 1988. Genetic analysis of glucose tolerance in inbred mouse strains. Evidence for polygenic control Diabetes $37,707-713$

Kanai, M., Hanashiro, Kn, Kim, S.H., Hanai, S., Boulares, A.H., Miwa, M., Fukasawa, K, 2007. Inhibition of Crm1-p53 interaction and nuclear export of p53 by poly(ADP-ribosyl)ation. Nat. Cell Biol. 9, 1175-1183

Kawamitsu, H., Hoshino, H., Okada, H., Miwa, M., Momoì, H., Sugimura, T., 1984 Monoclonal antibodies to poly(adenosine diphosphate ribose) recognize dif ferent structures. Blochemistry 23,3771-3777.

Kolthur-Seetharam, U., Dantzer, F., McBurney, M.W., de Murcia, G., Sassone-Corsi, P., 2006. Control of Alf - mediated cell death by the functional interplay of SIRT1 and PARP- 1 in response to DNA damage. Cell Cycle 5, 873-877.

Krawitt, EL. 2006. Autoimmune hepatitis. N. Engl. J. Med. 354, 54-66.

Lonskaya, I., Potaman, V.N., Shlyakhtenko, L. ., Oussatcheva, E.A., Lyubchenko, Y.L. Soldatenkov, V.A., 2005. Regulation of poly(ADP-ribose) polymerase-1 by DNA structure-specific binding. J. Biol. Chem. 280, 17076-17083.

Mangerich, A. Scherthan, H., Diefenbach, J., Kloz, U., van der Hoeven, F., Beneke, $S$. Bürkle, A, 2009. A caveat in mouse genelic engineering: ectopic gene targeting in ES cells by bidirectional extension of the homology arms of a gene replacement vector carrying human PARP-1. Transgenic Res. 18, 261-279.

Mantovani, A, Allavena, $P$., Sica, A., Balkwill, F, 2008. Cancer-related inflammation Nature $454_{i} 436-444$

Maronpot, RR, Boorman, G.A., Gaul, B.W., 1999. Pathology of the Mouse Cache River Press, Saint Louis.

Martin-Oliva, D., O'Valle, F. Munoz-Gamez, J.A., Valenzuela, M.T, Nunez, M. Aguilar, M., Ruiz de Almodovar, J.M., Garcia del Moral, R, Oliver, F.]., 2004 Crosstalk between PARP-1 and NF-KappaB modulates the promotion of skin neoplasia. Oncogene 23, 5275-5283.

Maslov, A.Y, Vijg, J., 2009. Genome instability, cancer and aging. Biochim. Biophys. Acta 1790, 963-969.

Masoro, E., 2006. Handbook of the biology of aging. Academic Press, Elsevier Burlington

Masutani, M., Suzuki, H., Kamada, N., Watanabe, M., Ueda, O., Nozaki, T, Jishage, K. Watanabe, T., Sugimoto, T., Nakagama, H., Ochiya, T., Sugimura, T., 1999 Poly(ADP-ribose) polymerase gene disruption conferred mice resistant to streptozotocin-induced diabetes. Proc. Natl. Acad. Sci, U.S.A. 96, 2301-2304.

Mendoza-Alvarez, H., Alvarez-Gonzalez, R, 1993. Poly(ADP-ribose) polymerase is catalytic dimer and the automodification reaction is intermolecular. $J$ Biol. Chem. 268, 22575-22580

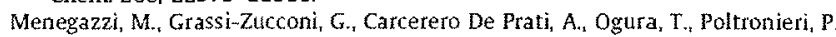
Nyunoya, H., Shiratori-Nyunoya, Y., Miwa, M., Suzuki, H., 1991. Differentia expression of poly(ADP-ribose) polymerase and DNA polymerase beta in ra tissues. Exp. Cell Res. 197, 66 74

Min, W. Wang, ZQ, 2009. Poly (ADP-ribose) glycohydrolase (PARG) and it therapeutic potential. Front. Biosci. 14, 1619-1626.

Moreno-Villanueva, M., Pfeiffer, R., Sindlinger, T., Leake, A., Muller, M., Kirkwood T.B. Bürkle, A, 2009. A modified and automated version of the 'fluorimetric detection of alkaline DNA unwinding' method to quantify formation and repai of DNA strand breaks. BMC Biotechnot, 9, 39.

Muiras, M.L., Muller, M., Schachter, F., Burkle, A, 1998. Increased poly(ADP.ribose polymerase activity in lymphoblastoid cell lines from centenarians. I. Mol. Med. $76,346-354$

Oei, S.L., Herzog, H., Hirsch-Kauffmann, M., Schneider, R, Auer, B., Schweiger, M. 1994. Transcriptional regulation and autoregulation of the human gene fo ADP-ribosyltransferase. Mol. Cell Biochem. 138, 99-104.

Ogura, T., Takenouchi, N., Yamaguchi, M. Matsukage, A., Sugimura, T, Esumi, H, 1990. Striking similarity of the distribution patterns of the poly/ADP-ribose) polymerase and DNA polymerase beta among various mouse organs. Biochem. Biophys. Res. Commun. 172, 377-384.

Pieper, A.A., Brat, D.J., Krug. D.K., Watkins, C.C., Gupta, A., Blackshaw, S., Verma, A. Wang, Z.Q. Snyder, S.H., 1999. Poly(ADP-ribose) polymerase-deficient mice are protected from streptozotocin-induced diabetes. Proc Natl. Acad. Sci. U.S.A. 96 3059-3064.

Pillai, J.B., Isbatan, A., Imai, S., Gupta, M.P., 2005. Poly(ADP-ribose) polymerase-1 dependentcardiac myocyte cell death during heart failure is mediated by NAD+ depletion and reduced Sir 2 alpha deacerylase activity. J. Biol. Chem. 280, 4312143130

Pion, E., Ulimann, G.M., Ame, J.C., Gerard, D., de Murcia, G., Bombarda, E., 2005. DNAinduced dimerization of poly (ADP-ribose) polymerase-1 triggers its activation. Biochemistry 44, 14670 14681.

Piskunova, T.S., Yurova, M.N., Ovsyannikov, A.l, Semenchenko, A.V., Zabezhinski, M.A., Popovich, I.G. Wang, Z.,., Anisimov, V.N., 2008. Deficiency in poly(ADPribose) polymerase- 1 (PARP-I) accelerates aging and spontaneous carcinogen esis in mice. Curr. Gerontol. Geriatrics Res. 2008, 754190.

Pleschke, J.M. Kleczkowska, H.E., Strohm, M., Althaus, F.R, 2000. Poly(ADP-ribose) binds to specific domains in DNA damage checkpoint proteins. 1. Biol. Chem. $275,40974-40980$

Radovits, T., Seres, L., Gero, D., Berger, 1., Szabo, C., Karck, M., Szabo, G., 2007. Single dose treatment with PARP-inhibitor INO-1001 improves aging-associated cardiac and vascular dysfunction. Exp. Gerontol. 42,676-685.

Rajamohan, S.B., Pillai, V.B., Gupta, M., Sundaresan, N.R. Konstatin, B., Samant, S. Hottiger, M.O., Gupta, M.P., 2009. SIRT1 promotes cell survival under stress by deacetylation-dependent deactivation of poly (ADP-ribose) polymerase 1. Mol. Cell Biol. $29,4116-4129$. 
Razzaque, M.S., Sitara, D., Taguchi, T., St-Arnaud, R, Lanske, B, 2006. Premature aging-like phenotype in fibroblast growth factor 23 null mice is a vitamin $D$ mediated process. FASEB J. 20, 720-722.

Rosen, E.D., Spiegelman, B.M., 2006 . Adipocytes as regulators of energy balance and glucose homeostasis. Nature 444, 847-853.

Rouleau, M., Patel, A., Hendzel, M.J., Kaufmann, S.H., Poirier, G.G., 2010. PARP inhibition: PARP1 and beyond. Nat. Rev. Cancer 10, 293-301.

Ruscetti, T. Lehnert, B.E, Halbrook, I. Le Trong, H., Hoekstra, M.F., Chen, D. . Peterson, S.R. 1998. Stimulation of the DNA-dependent protein kinase by poly(ADP-ribose) polymerase. J. Biol. Chem. 273, 14461-14467.

Schreiber, V., Dantzer, F. Ame, J.-C de Murcia, G., 2005. Poly(ADP-ribose): novel functions for an old molectle Nat. Rev. Mol. Cell Biol. 7, 517-528.

Shall, S., de Murcia, G. 2000. Poly(ADP-ribose) polymerase-1: what have we learned from the deficient mouse model? Mutat. Res. 460, 1-15.

Shieh, W.M., Ame, J.C. Wilson, M.V., Wang, Z.Q, Koh, D.W., Jacobson, M.K. Jacobson, E.L, 1998. Poly (ADP-ribose) polymerase null mouse cells synthesize ADP-ribose polymers. J. Biol. Chem. 273, 30069-30072.

Soldatenkov, V.A., Chasovskikh, S., Potaman, V.N., Trofimova, I, Smulson, M.E Dritschila, A., 2002. Transcriptional repression by binding of poly(ADP-ribose) polymerase to promoter sequences. J. Biol. Chem. 277, 665-670.

Son, J., Pang, B., McFaline, J.L, Taghizadeh, K., Dedon, P.C, 2008. Surveying the damage: the challenges of developing nucleic acid bionarkers of inflammation. Mol. Biosyst. 4, 902 -908

Stilmann, M., Hinz, M., Arslan, S.C., Zimmer, A., Schreiber, V., Scheidereit, C., 2009. A nuclear poly(ADP-ribose)-dependent signalosome confers DNA damage-induced IkappaB kinase activation. Mol. Cell 36, 365-378.

Szabo, C., 2005. Roles of poly(ADP-ribose) polymerase activation in the pathogenesis of diabetes mellitus and its complications. Pharmacol. Res. 52,60-71.

Szabo, C., Zanchi, A., Konjati, K., Pacher, P., Krolewski, A.S., Quist, W.C., LoGerfo, F.W. Horton, E.S., Veves, A., 2002. Poly(ADP-Ribose) polymerase is activated in subjects at risk of developing type 2 diabetes and is associated with impaired vascular reactivity. Circulation 106, 2680-2686.

Tao, Z., Gao, P. Liu, H.W., 2009. Identification of the ADP-ribosylation sites in the PARP- 1 automodification domain: Analysis and implications. J. Am. Chem. Soc. $14,14258-14260$.

Tempera, l., Cipriani, R., Campagna, G., Mancini, P., Gatti, A., Guidobaldi, L. Pantellini, F., Mandosi, E., Sensi, M., Quesada, P., Mario, U.D., D'Erme, M. Morano, S., 2005. Poly(ADP-ribose)polymerase activity is reduced in circulating mononuclear cells from type 2 diabetic patients. J. Cell. Physiol. 205,387392 .
Tong, W.M., Cortes, U., Wang, Z.Q., 2001. Poly(ADP-ribose) polymerase: a guardian angel protecting the genome and suppressing tumorigenes is. Biochim. Biophys. Acta $1552,27-37$

Treuting, P.M., Linford, N.J., Knoblaugh, S.E., Emond, M.J., Morton, J.F, Martin, G.M. Rabinovitch, P.S., Ladiges, W.C. 2008. Reduction of age-associated pathology in old mice by overexpression of catalase in mitochondria. J. Gerontol. A Biol. Sci. Med. Sci. 63, 813-822.

Turusov, V.S., 1979. Pathology of tumous in laboratory animals. Vol. In - Tumours of the mouse. International agency for research on cancer, Lyon.

Tyner, S.D., Venkatachalam, S., Choi, J., Jones, S., Ghebranious, N., Igelmann, H., Lu, X


Bradley, A., Donehower, L.A., 2002. p53 mutant mice that display early ageing-associated phenotypes. Nature $415,45-53$.

Vidakovic, M. Gluch, A., Qiao, J., Oumard. A. Frisch. M., Poznanovic, G., Bode, I. 2009. PARP-1 expression in the mouse is controlled by an autoregulatory loop: PARP-1 binding to an upstream S/MAR-element and to a novel recognition motif in its promoter suppresses transcription. J. Mol. Biol. 388, 730-750.

von Kobbe, C., Harrigan, J.A., May, A., Opresko, P.L., Dawut, L., Cheng, W.H., Bohr $V$ A. 2003. Central role for the Werner syndrome protein/poly(ADP-ribose) polymerase 1 complex in the poly(ADP-ribosyl zation pathway after DNA damage Mol Cell. Biol. 23, 8601-8613.

von Kobbe, C., Harrigan, J.A., Schreiber, V., Stiegter, P., Piotrowski, J., Dawut, L., Bohr V.A., 2004 . Poly(ADP-ribose) polymerase 1 regulates both the exonuclease and helicase activities of the Werner syndrome protein. Nucleic Acids Res. 32, 40034014.

yon Lukowicz, T., Hassa, P.O., Lohmann, C, Boren, I., Braunersreuther, V., Mach, F, Odermatt, B., Gersbach, M., Canici, G.G., Stahli, B.E., Tanner, F.C., Hottiger, M.O., Luscher, T.F., Matter, CM., 2008. PARP1 is required for adhesion molecule expression in atherogenesis. Cardiovasc. Res. 78, 158-166.

Wang, ZQ., Auer, B., Stingl, L, Berghammer, H., Haidacher, D., Schweiger, M. Wagner, E.F., 1995. Mice lacking ADPRT and poly(ADP-ribosyl)ation develop normally but are susceptible to skin disease. Genes Dev. 9, 509-520.

Ward, J.M. Mahler, J.F., Maronpot, R R, Sundberg, I.P., 2000. Pathology of Genetically Engineered Mice. lowa State University Press, Ames.

Zarychanski, R, Houston, D.S., 2008. Anemia of chronic disease: a harmful disorder or an adaptive, beneficial response? CMAI 179, 333-337.

Zhao, H., Przybylska, M., Wu, I.H., Zhang, I, Siegel, C., Komarnitsky, S., Yew, N.S Cheng, S.H., 2007. Inhibiting glycosphingolipid synthesis improves glycemic control and insulin sensitivity in animal models of type 2 diabetes. Diabetes 56 , $1210-1218$. 